\title{
LA NATURALEZA IMPERATIVA DEL PRINCIPIO “NO HAY PAZ SIN JUSTICIA" RESPECTO A LOS MÁXIMOS RESPONSABLES DEL FENÓMENO DE LA LESA HUMANIDAD Y SUS CONSECUENCIAS PARA EL ÁMBITO DE ACTUACIÓN DE LA LLAMADA “JUSTICIA DE TRANSICIÓN"1
}

\section{THE PEREMPTORY NATURE OF THE PRINCIPLE "NO PEACE WITHOUT JUSTICE" WITH RESPECT TO THOSE MOST RESPONSIBLE PERSONS FOR CRIMES AGAINST HUMANITY AND THE CONSEQUENCES FOR THE SCOPE OF APPLICATION OF THE SO CALLED "TRANSITIONAL JUSTICE"}

Héctor OLASOLO ALONSO ${ }^{2}$

Andrea MATEUS RUGELES ${ }^{3}$

Andrés CONTRERAS FONSECA ${ }^{4}$

RESUMEN: El texto aborda el carácter imperativo de la prohibición en el derecho internacional de la comisión de crímenes de lesa humanidad, así como la obligación que dé juzgamiento, investigación y sanción de las conductas que constituyen estos crímenes. Asimismo, analiza cómo el concepto de justicia transicional tiene una naturaleza complementaria frente a las mencionadas obligaciones, lo que hace que todo proceso de justicia de transición tenga que construirse en torno al paradigma "no hay paz sin justicia", y no en sustitución del mismo.

\footnotetext{
${ }^{1}$ Artículo recibido el 8 de diciembre de 2014 y aceptado para su publicación el 1o. de junio de 2015.

2 Magíster en derecho por Universidad de Columbia (Nueva York) y licenciado y doctor por la Universidad de Salamanca (España). En la actualidad se desempeña como profesor titular de carrera y director de la Clínica Jurídica Internacional de la Facultad de Jurisprudencia de la Universidad del Rosario (Bogotá, Colombia); presidente del Instituto Iberoamericano de La Haya para la Paz, los Derechos Humanos y la Justicia Internacional (IIH) y director del Anuario Iberoamericano de Derecho Internacional Penal (ANIDIP), hectorolasolo@gmail.com.

${ }^{3}$ Magíster en derecho internacional por la Universidad de Nueva York, Estados Unidos. Abogada de la Universidad del Rosario (Bogotá, Colombia). Profesora principal de carrera académica en la Facultad de Jurisprudencia de la Universidad del Rosario y coordinadora del área de Derecho Internacional de la misma Facultad, andrea.mateus@urosario.edu.co.

${ }^{4}$ Estudiante del programa de Doctorado en Derecho en la Universidad de los Andes (Colombia) y magíster cum laude en derecho internacional de la misma Universidad. Abogado de la Universidad del Rosario. Miembro del Grupo de Investigación en Derecho y Acción Social de la Universidad de los Andes. Profesor de los programas de especialización en derecho constitucional y derecho internacional de los derechos humanos en la Universidad del Rosario, Colombia, ja.contreras10@uniandes.edu.co.
} 
Esta revista forma parte del acervo de la Biblioteca Jurídica Virtual del Instituto de Investigaciones Jurídicas de la UNAM

Palabras clave: normas imperativas, ius cogens, crímenes de lesa humanidad, derecho internacional penal, obligación de investigar, justicia transicional

ABSTRACT: This text studies the imperative nature of the prohibition of committing crimes against humanity in international law, and the obligation to prosecute, judge, and punish these crimes. In this way, it develops the complementarity of transitional justice with the abovementioned obligations. These results in the conclusion that transitional justice processes have to be built on the paradigm of "no peace without justice" and not the other way around.

Keywords: Imperative Law, Ius Cogens, Crimes Against Humanity, International Criminal Law, Transitional Justice.

SUMARIO: I. Introducción. II. La regulación del fenómeno de la lesa humanidad y sus efectos jurídicos en el derecho internacional general y convencional. III. Concepto y desarrollo de/ius cogens en el derecho internacional. IV. La naturaleza de ius cogens de la normativa que regula el fenómeno de la lesa humanidad y sus efectos jurídicos. V. La naturaleza no imperativa del concepto de justicia de transición. VI. Conclusiones. VII. Bibliografía.

\section{INTRODUCCIÓN}

Al término de la Segunda Guerra Mundial, el temor a un nuevo conflicto armado de carácter global que destruyera definitivamente el planeta provocó la puesta en marcha en la sociedad internacional de un mecanismo centralizado de declaración y realización de la responsabilidad internacional penal en la que habían incurrido los dirigentes de Alemania y Japón, al generar una guerra de agresión y desarrollar campañas de violencia sistemática y generalizada contra la población civil, que provocaría millones de muertos. Con ello, la sociedad internacional enviaba el mensaje de que quienes utilizaban los resortes del poder para llevar a cabo este tipo de comportamientos no sólo perdían la legitimidad ética y moral necesaria para seguir dirigiendo sus respectivas sociedades, sino que debido al daño que causan a la sociedad internacional en su conjunto incurrían jurídicamente en responsabilidad internacional individual de carácter penal, que, como se afirmaría años después en $1968,{ }^{5}$ no se extingue bajo ninguna circunstancia. ${ }^{6}$

\footnotetext{
${ }^{5}$ Convención sobre la Imprescriptibilidad de los Crímenes de Guerra y de los de Lesa Humanidad, adoptada y abierta a firma, ratificación y adhesión por la Asamblea General en su resolución 2391 (XXIII), del 26 de noviembre de 1968, y que entró en vigor el 11 de noviembre de 1970.

${ }^{6}$ Olasolo, Héctor, "Dignidad humana, derecho internacional penal y justicia transicional”, Estudios Socio-Jurídicos, Bogotá, vol. 16, 2014, pp. 13-21; reimpreso en Olasolo, Héctor, Introducción al derecho internacional penal, México,
} 
Esta revista forma parte del acervo de la Biblioteca Jurídica Virtual del Instituto de Investigaciones Jurídicas de la UNAM

Es en este marco jurídico en el que surgieron los deberes de los Estados a no incurrir a través de sus agentes en graves violaciones de derechos humanos frente a quienes se encuentren bajo su jurisdicción (en particular, campañas de violencia sistemática o generalizada contra la población civil), así como a adoptar todas las medidas que estén a su disposición para prevenirlas y, en caso de que finalmente lleguen a producirse, investigarlas, juzgarlas y sancionarlas, además de reparar a las víctimas. ${ }^{7}$ Correlativamente a estas obligaciones estatales, se desarrollaron los derechos a la verdad, la justicia y la reparación de las personas que hubieran sufrido estas atrocidades. ${ }^{8}$

Lo que resultaba realmente innovador del nuevo derecho internacional penal es que, a diferencia del derecho nacional penal (que se dirige a la inmensa mayoría de seres humanos encuadrados en la categoría de "ciudadanos normales", tal como fuera desarrollada por Hanna Arendt, ${ }^{9}$ o en la categoría de "no ciudadanos" propia de la doctrina de la seguridad nacional), ${ }^{10}$ se dirigía, en particular, a todos aquellos que tradicionalmente han estado por encima de la ley en virtud del concepto de “razón de

Tirant lo Blanch, Casa Editorial de la Universidad del Rosario e Instituto Ibero-Americano de La Haya (IIH), 2014, pp. 27 y ss.

${ }^{7}$ Werle, Gerad, Tratado de derecho penal internacional, Valencia, Tirant lo Blanch, 2a. ed., 2010, pp. 133-147.

${ }^{8}$ González Morales, Felipe, Sistema inter-americano de derechos humanos: transformaciones y desafíos, Valencia, Tirant lo Blanch, 2013, pp. 264-291; también Olasolo, Héctor, "Los exámenes preliminares de la Corte Penal Internacional en América Latina: el caso colombiano y su impacto sobre futuras negociaciones de paz en la región", Anuario de Derechos Humanos, Santiago, núm. 14, 2014, pp. 35-56.

${ }^{9}$ Arendt, Hanna, Eichmann in Jerusalem: a Report on the Banality of Evil, Penguin Group, 1963.

${ }^{10}$ Esta teoría se encuentra ampliamente expuesta por Jakobs, Gunther Cancio Meliá, Manuel, Derecho penal del enemigo, Madrid, Civitas, 2006. Una aplicación de la misma se encuentra en la Military Order, emitida el 13 de noviembre de 2001 por el presidente G. W. Bush, que faculta al gobierno de los Estados Unidos a arrestar a "nociudadanos" de quienes se tengan "razones para creer" que son terroristas, a los efectos de que puedan ser procesados por un tribunal militar. Los juicios son secretos, y los fiscales no están obligados a presentar pruebas si esto es "en pos de los intereses de la seguridad nacional". Vervaele, John, "La legislación antiterrorista en Estados Unidos: inter arma silent leges", Madrid, Revista de Derecho y Proceso Penal, núm. 14, 2005, pp. 116 y ss. Para una aproximación crítica a la doctrina de la seguridad nacional, Bustos Ramírez, J., "In-seguridad y la lucha contra el terrorismo", en Losano y Muñoz Conde (coords.), El derecho ante la globalización y el terrorismo, “cedant arma togae”, Valencia, Tirant lo Blanch, 2004, p. 407; Zaffaroni, E. R. et al., Derecho penal. Parte general, Buenos Aires, Ediar, 2000, p. 17; Muñoz Conde, Fernando, "El nuevo derecho penal autoritario", en Cortes Bechiarelli, E., Octavio de Toledo, E. et al. (coords.), Estudios penales en recuerdo del profesor Ruiz Antón, Valencia, Tirant lo Blanch, 2003, Olasolo, Héctor y Pérez Cepeda, Ana, Terrorismo y conflicto armado, Valencia, Tirant lo Blanch, 2008, cap. II. 
Esta revista forma parte del acervo de la Biblioteca Jurídica Virtual del Instituto de Investigaciones Jurídicas de la UNAM

Estado": ${ }^{11}$ los denominados "máximos responsables", ${ }^{12}$ que utilizan los resortes del poder para hacer que los "ciudadanos normales" lleven a cabo acríticamente las más horrorosas atrocidades contra sus semejantes. ${ }^{13}$

Sin embargo, la aparición del derecho internacional penal y sus mecanismos de aplicación no pudieron evitar que durante la guerra fría, que tuvo lugar entre 1949 y 1989, la impunidad de los máximos responsables de campañas de violencia sistemática o generalizada contra la población civil fuera cercana a un $100 \%$, y decenas de millones de víctimas fueran sistemáticamente olvidadas y dejadas a su suerte. ${ }^{14}$ Esta situación se prolongó hasta que, en 1993, el Consejo de Seguridad de las Naciones Unidas decidiera por primera vez desde su creación en 1945, establecer tribunales internacionales penales para investigar y enjuiciar a los responsables de genocidio, crímenes de lesa humanidad y crímenes de guerra cometidos en ciertas partes del mundo. ${ }^{15}$

\footnotetext{
${ }^{11}$ Siguiendo las categorías de Arendt, se trata de aquellos "dogmáticos" (que suplen su angustia de convivir con la incertidumbre por la férrea adopción de un ideal, a cuya realización subyugan todos los demás valores) y "nihilistas" (que no creen en nada sino en sí mismos, lo que les lleva a hacer todo lo que sea necesario para satisfacer sus propias ambiciones de ascenso social y poder político y económico) que utilizan los resortes del poder para hacer que los “ciudadanos normales" lleven a cabo acríticamente las más horrorosas atrocidades contra sus semejantes. Arendt, H., Eichmann in Jerusalem, op. cit.
}

${ }^{12}$ La Fiscalía de la CPI ha utilizado la expresión "máximos responsables" como criterio de política criminal para delimitar el ámbito de actuación del ejercicio de sus funciones de investigación y enjuiciamiento de los delitos de genocidio, lesa humanidad y crímenes de guerra. Fiscalía de la CPI, Paper on some Policy Issues before the Office of the Prosecutor, ICC-OTP 2003, septiembre de 2003; Fiscalía de la CPI, Report on Prosecutorial Strategy, 14 de septiembre de 2006 y Fiscalía de la CPI, Policy Paper on the Interests of Justice, ICC-OTP 2007, septiembre de 2007. Una expresión similar (most senior leaders) había sido ya utilizada por el Consejo de Seguridad de las Naciones Unidas en el párrafo 5 de su Resolución 1534 de 26 de marzo de 2004, para redefinir el alcance de la jurisdicción personal de los Tribunales Internacionales Penales para la ex Yugoslavia y Ruanda.

${ }^{13}$ Olasolo, Héctor, Dignidad humana, derecho internacional penal y justicia transicional, cit., pp. 13-21; reimpreso en Olasolo, H., Introducción al derecho internacional penal, cit., pp. 27 y ss.

${ }^{14}$ Sólo el número de víctimas mortales se estima en torno a los 18 millones de personas.

${ }^{15}$ Así, se crearon los tribunales internacionales penales para la ex Yugoslavia (TIPY) y Ruanda (TIPR) y el Tribunal Especial del Líbano (TEL). Además, el secretario general de las Naciones Unidas participó activamente en la creación de tribunales mixtos e internacionalizados como el Tribunal Especial para Sierra Leona (TESL), las Salas Extraordinarias de los Tribunales de Camboya (SETC) y las salas de crímenes de guerra de Timor Oriental, BosniaHerzegovina, o Kosovo. Se llegaron incluso a crear organismos especializados para su actuación ante las jurisdicciones nacionales, como es el caso de la Comisión Internacional contra la Impunidad en Guatemala. 
Esta revista forma parte del acervo de la Biblioteca Jurídica Virtual del Instituto de Investigaciones Jurídicas de la UNAM

La efectiva puesta en marcha de la Corte Penal Internacional (CPI) durante la primera década del siglo XXI supone un paso fundamental en este proceso, al constituir una jurisdicción permanente para la declaración y realización de la responsabilidad internacional penal de aquellos líderes políticos, militares y económicos que desde el poder estatal, o no estatal, planean, promueven y favorecen con sus acciones $u$ omisiones el desarrollo de violencia sistemática o a gran escala constitutiva de genocidio, lesa humanidad y crímenes de guerra. ${ }^{16}$ En consecuencia, se puede afirmar que desde mediados de los años noventa hasta la actualidad, se ha reafirmado el paradigma de que la dirigencia que desde los resortes del poder recurre a este tipo de violencia no sólo pierde toda legitimidad ética y moral para seguir dirigiendo sus respectivas sociedades, sino que incurre jurídicamente en responsabilidad internacional penal frente al conjunto de la sociedad internacional.

La reafirmación de este paradigma, con los deberes de los Estados y los derechos de las víctimas que el mismo implica, no ha sido pacífica, puesto que desde el concepto de "justicia de transición" se ha venido afirmando una presunta imposibilidad de los Estados para cambiar de régimen político o alcanzar la paz en contextos en los que se han producido violaciones graves y sistemáticas de derechos humanos, sin que se permita una "flexibilización" de los estándares de investigación, juzgamiento y sanción de los responsables de crímenes internacionales.

En este contexto, Colombia es un caso emblemático en América Latina, como lo demuestra el llamado "Marco Jurídico para la Paz", aprobado a través del Acto Legislativo 10. de 2012, por el que se introducen dos artículos transitorios (66 y 67) a la Constitución Política de Colombia. En estos artículos se recoge toda una "estrategia de justicia transicional", que consiste en la creación de una Comisión de la Verdad y un régimen de reparaciones en vía administrativa, el establecimiento de criterios de selección y priorización de casos, la previsión de penas alternativas y regímenes especiales de suspensión y ejecución de penas en los casos seleccionados, y el establecimiento de un sistema de sanciones extrajudiciales para los casos no seleccionados. ${ }^{17}$

\footnotetext{
${ }^{16}$ Preámbulo y artículo 1o. del Estatuto de la Corte Penal Internacional.

${ }^{17}$ A este respecto, Fiscalía de la CPI, Situación en Colombia, Reporte Intermedio, noviembre de 2012, disponible en http://www.icc-cpi.int/NR/rdonlyres/C433C462-7C4E-4358-8A72
}

8D99FD00E8CD/285209/OTP2012ReportonPreliminaryExaminations22Nov2012.pdf. 
Esta revista forma parte del acervo de la Biblioteca Jurídica Virtual del Instituto de Investigaciones Jurídicas de la UNAM

Sin embargo, al analizar su contenido nos encontramos con que las elaboraciones propuestas hasta el momento desde la justicia de transición tienen como fundamento medidas de política pública que, en buena medida, menoscaban el paradigma que exige a los máximos responsables (de campañas de violencia sistemática o generalizada contra la población civil) dejar inmediatamente sus posiciones de liderazgo y hacer frente a la responsabilidad penal asumida frente a su propia sociedad y a la sociedad internacional en su conjunto. ${ }^{18}$

En este contexto, el presente trabajo analiza la consolidación de este último paradigma y sus efectos en el derecho internacional general y convencional. Asimismo, estudia hasta qué punto dicha regulación ha adquirido el carácter de derecho imperativo o de ius cogens. Finalmente, analiza el concepto de justicia de transición y las medidas de política pública que se engloban en el mismo, así como su apoyo normativo en el derecho internacional, a los efectos de determinar la necesidad o no de redireccionarlas hacia la búsqueda de fórmulas, que partiendo epistemológicamente del paradigma "no hay paz sin justicia" como condición de validez, permitan aligerar algunas de las tensiones observadas en los actuales procesos de transición.

\section{LA REGULACIÓN DEL FENÓMENO DE LA LESA HUMANIDAD Y SUS EFECTOS JURÍDICOS EN EL DERECHO INTERNACIONAL GENERAL Y CONVENCIONAL}

\footnotetext{
${ }^{18}$ Entre las medidas adoptadas, para la Fiscalía, serían particularmente preocupantes las relativas a la selección y priorización de casos. En particular, cabe destacar la atribución del Congreso de la República para centrar por vía legislativa los esfuerzos de investigación y enjuiciamiento penal en los máximos responsables de aquellos delitos constitutivos de genocidio, lesa humanidad y crímenes de guerra, que sean cometidos de manera sistemática, tengan la gravedad suficiente y supongan casos representativos de la violencia acaecida en Colombia (selección de casos). Esta facultad viene acompañada de la atribución del propio Congreso de la República para renunciar por vía legislativa al ejercicio de la acción penal de todos los casos no seleccionados. Además, se reconoce a la Fiscalía General de la Nación la competencia para establecer cualquiera criterios de priorización que considere oportunos en relación con aquellos casos que han sido seleccionados por el Congreso de la República. Frente a estas medidas, la Fiscalía de la CPI hace hincapié en el riesgo de impunidad frente a superiores medios y autores materiales a los que puede llevar la articulación práctica de los mencionados criterios de selección y priorización. La Fiscalía de la CPI muestra también su preocupación por la aplicación de penas alternativas en los casos seleccionados, así como por los regímenes de suspensión y ejecución especial de las penas. Fiscalía de la CPI. Situación en Colombia, Reporte Intermedio, cit., pfos. 201-204. Para un estudio más detallado, Héctor Olasolo, Los exámenes preliminares en América Latina: el caso colombiano y su impacto sobre futuras negociaciones de paz en la región, cit.
} 
Esta revista forma parte del acervo de la Biblioteca Jurídica Virtual del Instituto de Investigaciones Jurídicas de la UNAM

Tras la sentencia proferida el 10. de octubre de 1946 por el Tribunal de Núremberg, ${ }^{19}$ la Asamblea General de las Naciones Unidas reafirmó en su Resolución 95 (I) del 11 de diciembre de 1945, los principios de derecho internacional reconocidos en el estatuto y sentencia del TMI (conocidos como "principios de Núremberg"), ${ }^{20}$ entre los que se encontraba el reconocimiento del carácter internacional de la categoría de los delitos de lesa humanidad. ${ }^{21}$ La Resolución 95 (I) fue seguida por la Resolución 177 (II), de 21 de noviembre de 1947, por la que se instruía a la recién creada Comisión de Derecho Internacional (CDI) que formulara y desarrollara los principios de Núremberg y preparara un Código de Crímenes Internacionales. ${ }^{22}$

En 1950, la CDI presentó a la Asamblea General su informe sobre los principios de Núremberg, en el que se reconoce que aquellas situaciones en las que se producen múltiples actos de violencia sistemática o de gran escala contra la población civil de

${ }^{19}$ Sentencia del Tribunal Militar Internacional de Núremberg, del 1o. de octubre de 1946. Año y medio después, el Tribunal Militar Internacional para el Lejano Oriente, dictaría su sentencia el 4 de noviembre de 1948.

${ }^{20}$ AGNU Res. 95 (I), del 11 de diciembre de 1946.

${ }^{21}$ Idem. El primer antecedente de la categoría de los delitos de lesa humanidad se remonta a 1915, cuando los gobiernos de Francia, Reino Unido y Rusia realizaron una declaración conjunta afirmando que Turquía había cometido delitos que afectaban a la "conciencia de la humanidad" contra cerca de 800,000 armenios que habitaban en su territorio. Esta declaración se recoge en el memorándum armenio presentado el 14 de marzo de 1919 por la delegación griega a la Commission on the Responsibilities of Authors of the War and on the Enforcement of Penalties (conocida como Comisión de Responsabilidades), formada por los Estados aliados al final de la Primera Guerra Mundial. Este memorándum se encuentra en Schwelb, Egon, Crimes Against Humanity, Londres, British Yearbook of International Law, núm. 23, 178, 1946, pp. 178 y 181. También a este respecto entre otros, Dadrian, Vahakam, "Genocide as a problem of national and international law: the World War I armenian case and its contemporary legal ramifications", Yale Journal of International Law, núm. 14, 221, 1989; posteriormente, al término de la I Guerra Mundial en 1918, el proyecto de Tratado de Sevres afirmaba el derecho de las potencias vencedoras a enjuiciar a los responsables de tales delitos, y la obligación de Turquía de entregar a los miembros del gobierno turco y de sus fuerzas armadas que los habían incitado. Matas, $\mathrm{Da}$, "Prosecuting crimes against humanity: the lessons of World War I", Fordham International Law Journal, núm. 13, 86, 1990. El proyecto no llegó a entrar en vigor porque Estados Unidos y Japón se opusieron al mismo al considerar que la categoría de delitos contra la conciencia de la humanidad no había sido definida a nivel internacional con anterioridad a la violencia ejercida contra los armenios residentes en Turquía. Bassiouni, Cherif, Crimes Against Humanity-Historical Evolution and Contemporary Application, Cambridge, Cambridge University Press, 2011, pp. 88 y 89. Sin embargo, fueron los Estados Unidos quienes 25 años después se convertirían en los grandes precursores del Tribunal Militar Internacional de Núremberg (TMI) que, establecido en 1945 a través del Tratado de Londres, juzgaría a los más altos dirigentes políticos y militares del régimen nazi por el delito de agresión y crímenes de lesa humanidad y de guerra cometidos durante la Segunda Guerra Mundial.

${ }^{22}$ AGNU Res. 177 (II), del 21 de noviembre de 1947. 
Esta revista forma parte del acervo de la Biblioteca Jurídica Virtual del Instituto de Investigaciones Jurídicas de la UNAM

un Estado, no son más una cuestión meramente interna de dicho Estado, sino que se convierten en un asunto de la sociedad internacional en su conjunto, pues menoscaban los valores básicos sobre los que ésta se organiza. ${ }^{23}$ En consecuencia, quienes incurren en estos comportamientos se convierten en "enemigos de la humanidad", lo que hace que deban ser investigados y enjuiciados por los Estados actuando en nombre de la sociedad internacional. ${ }^{24}$ Asimismo, cuando se crea un tribunal internacional penal, los Estados afectados tienen la obligación de cooperar con el mismo en sus actuaciones. ${ }^{25}$ Finalmente, debido a que en su origen los delitos de lesa humanidad fueron cometidos a través de instituciones estatales, que daban a los mismos un "barniz de legalidad", también se incorporó el principio por el que la comisión de este tipo de delitos no depende de su prohibición en la normativa interna del Estado afectado, sino que, por el contrario, la legislación nacional es considerada irrelevante a los efectos de determinar si sus dirigentes habían incurrido en delitos de lesa humanidad. ${ }^{26}$

A pesar de que la Asamblea General de las Naciones Unidas, en su Resolución 488 (V), del 12 de diciembre de $1950,{ }^{27}$ no adoptó formalmente la versión más elaborada de los principios Núremberg presentada por la Comisión de Derecho Internacional (CDI) en 1950 (invitando meramente a los Estados a formular observaciones al informe presentado por la CDI), ${ }^{28}$ Bassiouni subraya que la mayoría de la doctrina atribuye un valor determinante al informe de la CDI como prueba de que los

\footnotetext{
${ }^{23}$ ILC Commission Report "Principles of international law recognized in the Charter of the Nurernberg Tribunal and in the judgment of the tribunal”, U. N. Dovs. núm. A/1316 (A/5/12), pfos. 95-127, que se pueden encontrar en el volumen 2 (1950) del Anuario de la Comisión de Derecho Internacional (Yearbook de la International Law Commission).

${ }^{24}$ Bassiouni, Cherif, Crimes Against Humanity-Historical Evolution and Contemporary Application, cit., pp. 177204. En su sesión de 2005 celebrada en Cracovia, el Instituto de Derecho Internacional afirmó la competencia universal sobre los delitos de lesa humanidad. Como ha sido señalado a este respecto, "[e]1 DI General es en este punto permisivo, siendo una cuestión de soberanía legislativa de cada Estado asumir el principio de universalidad, modular su alcance y condicionar su aplicación, atendiendo a su implicación en la protección de los derechos humanos y sus consecuencias de política exterior, en particular su incidencia sobre la satisfacción de otros objetivos". Brotons, Remiro y otros, Derecho internacional, 2a. ed., Valencia, Tirant lo Blanch, 2007, p. 134.

${ }^{25}$ Idem.

${ }^{26}$ Idem.

${ }^{27}$ AGNU Res. 488(V), del 12 de diciembre de 1950.

${ }^{28}$ Idem.
} 
Esta revista forma parte del acervo de la Biblioteca Jurídica Virtual del Instituto de Investigaciones Jurídicas de la UNAM

principios de Núremberg eran, ya en 1950, parte del derecho internacional general en calidad de costumbre internacional o de principio general del derecho. ${ }^{29}$ Es por esta razón que en 1968 se aprobó la Convención de Naciones Unidas sobre la Imprescriptibilidad de los Delitos de Lesa Humanidad y los Crímenes de Guerra. ${ }^{30}$

Los artículos 5o. del Estatuto del TPIY, 40. del Estatuto del TPIR, 7o. del Estatuto de la $\mathrm{CPI}^{31}$ y 2o. del Estatuto de la CESL han acogido la detallada elaboración que de la categoría de los delitos de lesa humanidad y sus efectos jurídicos había realizado el derecho internacional general al término de la Segunda Guerra Mundial. ${ }^{32}$ El carácter complementario de la CPI no sólo no afecta esta conclusión, sino que la refuerza, al atribuir a dicho órgano jurisdiccional la función de (i) recordar a los Estados parte sus deberes de investigación y enjuiciamiento de los máximos responsables de campañas de violencia sistemática o generalizada contra la población civil (así como de reparación a las víctimas); (ii) incentivarles en el cumplimiento de dichas obligaciones; y (iii) asumir dicho cumplimiento cuando compruebe inacción, falta de disposición o falta de capacidad de los propios Estados parte. ${ }^{33}$

Dicha conclusión tampoco se ve afectada por la concesión a la Fiscalía de la CPI del principio de oportunidad para el ejercicio de la acción penal conforme a los “intereses

\footnotetext{
${ }^{29}$ Bassiouni, Cherif, Crimes Against Humanity-Historical Evolution and Contemporary Application, cit., p. 174.

${ }^{30}$ Convención sobre la Imprescriptibilidad de los Crímenes de Guerra y de los de Lesa Humanidad, adoptada y abierta a firma, ratificación y adhesión por la Asamblea General en su resolución 2391 (XXIII), del 26 de noviembre de 1968, y que entró en vigor el 11 de noviembre de 1970, de conformidad con su artículo VIII.

${ }^{31}$ Conforme al párrafo 10. del artículo 7o. del Estatuto de la CPI, se entiende por delito de lesa humanidad "cualquiera de los actos siguientes cuando se cometa como parte de un ataque generalizado o sistemático contra una población civil y con conocimiento de dicho ataque”. Por su parte, el párrafo 2o. del artículo 7o. del Estatuto de la CPI afirma que por "ataque contra una población civil” se entenderá una línea de conducta que implique la comisión múltiple de actos mencionados en el párrafo 1o. contra una población civil, de conformidad con la política de un Estado o de una organización de cometer ese ataque o para promover esa política".

${ }^{32}$ Véase a este respecto, entre otros, Bassiouni, Cherif, "Accountability for Violations of International Humanitarian Law and other Serious Violations of Human Rights", en Bassiouni, Cherif, Post-conflict Justice, Transnational Publishers, Nueva York, Ardsley, 2002, pp. 3 y ss.; y Benavides Vanegas, Farid, Justicia en épocas de transición, conceptos, modelos, debates, experiencias, Barcelona, Institut Catalá International per la Pau, 2011, pp. 24 y 25.

${ }^{33}$ El Zeidy, Mohamed, The principle of complementarity in international criminal law. Origin, development and practice, Martinus Nijhoff Publishers, pp. 157 y 158. Olasolo, H., "Los exámenes preliminares de la Corte Penal Internacional en América Latina: el caso colombiano y su impacto sobre futuras negociaciones de paz en la región", Anuario de Derechos Humanos, vol. 10, 2014, pp. 35-56.
} 
Esta revista forma parte del acervo de la Biblioteca Jurídica Virtual del Instituto de Investigaciones Jurídicas de la UNAM

de la justicia", ${ }^{34}$ puesto que, como señala el documento de política criminal de la Fiscalía de la CPI sobre el contenido del concepto "intereses de la justicia", este concepto sólo permite que la Fiscalía deje de iniciar una investigación, o no impute a alguno de los "máximos responsables", debido a la falta de gravedad de los hechos, a las dificultades de acceso a los elementos de prueba o a los problemas de protección de los testigos y las víctimas. ${ }^{35}$

Finalmente, tampoco afecta al contenido de la regulación del fenómeno de lesa humanidad y sus efectos jurídicos según el derecho internacional general, el hecho de que el artículo 16 del Estatuto de la CPI atribuya al Consejo de Seguridad de las Naciones Unidas ${ }^{36}$ la facultad para poder solicitar a la CPI que suspenda durante un periodo prorrogable de doce meses cualquier investigación o enjuiciamiento en caso de que ello sea temporalmente necesario para no privar de eficacia a las medidas adoptadas por el propio Consejo en desarrollo de sus funciones de salvaguardia de la paz y la seguridad internacionales. ${ }^{37}$

En consecuencia, se puede afirmar que en la actualidad se encuentra consolidada, tanto en el derecho internacional general como en el derecho convencional, la regulación de la categoría de los crímenes de lesa humanidad y sus efectos jurídicos, entre los que cabe destacar: (i) la prohibición expresa de actos graves de violencia sistemática o generalizada contra la población civil; (ii) la atribución de responsabilidad internacional penal frente al conjunto de la sociedad internacional a los máximos responsables de tales conductas, y (iii) la imprescriptibilidad y prohibición de leyes de amnistía frente a dicha responsabilidad internacional penal.

\section{CONCEPTO Y DESARROLLO DEL IUS COGENSEN EL DERECHO INTERNACIONAL}

\footnotetext{
${ }^{34}$ Artículos 53 (1) y (2) del ER.

${ }^{35}$ Fiscalía de la CPI, Policy paper on the interests of justice, ICC-OTP 2007, septiembre de 2007. También, Stahn, Carsten, "Complementarity, amnesties and alternative forms of justice: some interpretative guidelines for the International Criminal Court", Journal of International Criminal Justice, Oxford, vol. 3, 2005, pp. 695 y ss.

${ }^{36}$ Los artículos 24, 25, 39 y 103 de la Carta de las Naciones Unidas configura al Consejo de Seguridad de las Naciones Unidas como el órgano de la sociedad internacional encargado del mantenimiento de la paz y la seguridad internacionales.

${ }^{37}$ Oosthiizen, Gabriel, "Some preliminary remarks on the relationship between the envisaged International Criminal Court and the UN Security Council”, Netherlands International Law Review, vol. 46, 1999, p. 313; Abass, Ademola, "The competence of the Security Council to terminate the jurisdiction of the International Criminal Court", Texas International Law Journal, vol. 40, 2005, pp. 263 y ss., y Olasolo, Héctor, Corte Penal Internacional: ¿dónde investigar?, Valencia, Tirant lo Blanch, 2003, cap. II, sec. IV.
} 
Esta revista forma parte del acervo de la Biblioteca Jurídica Virtual del Instituto de Investigaciones Jurídicas de la UNAM

Una vez afirmado que la regulación del fenómeno de la lesa humanidad y de sus efectos jurídicos son parte integral del derecho internacional general y convencional, analizaremos en la presente sección si dicha regulación ha adquirido el rango de ius cogens. Para ello, estudiaremos en primer lugar el origen y desarrollo del concepto de normas imperativas o de ius cogens, para extraer de éste los criterios que tendremos que aplicar para responder a nuestra pregunta.

\section{Concepto de ius cogens}

En la teoría del derecho internacional, la concepción de normas superiores de carácter inderogable para todos los actores internacionales se remonta a los escritos de Francisco de Vitoria. ${ }^{38}$ Éstos recogen normas derivadas del derecho natural, o divino, que se configuran como verdadero derecho inderogable. Además, y como algo diferenciado, Vitoria se refiere a un derecho de gentes creado por "todo el orbe", que da las leyes justas y a todos convenientes. ${ }^{39}$ Éste se encontraría formado por un conjunto de normas generales de obligatorio cumplimiento, que las naciones podrían cambiar, y que se asemejaría a la concepción moderna de normas erga omnes. ${ }^{40}$

La expresión normas de ius cogens fue utilizada por primera vez en el sentido que hoy la conocemos, por Alfred von Verdross, en 1937, al preguntarse si la libertad de los Estados para crear tratados en el derecho internacional podría tener algún límite emanado del derecho internacional general. Para Verdross, existen ciertas condiciones necesarias para la creación de tratados, como son las relativas al tipo de sujetos que tienen capacidad para crearlo, las condiciones intrínsecas y extrínsecas que se deben cumplir para que entren en vigor y las consecuencias de su terminación. Todas estas normas harían parte de un derecho internacional general, que no estaría escrito y que sería válido a pesar de su carácter no escrito. ${ }^{41}$ Además, también sería parte del mismo el principio que prohíbe la celebración de tratados contra las buenas costumbres, ${ }^{42}$ las cuales surgirían de un consenso tácito entre los Estados, derivado de los mínimos éticos comunes a todos los ordenamientos jurídicos. ${ }^{43}$

\footnotetext{
${ }^{38}$ Dominico español (1480-1546). Es conocido como el padre del derecho internacional. Sus trabajos principales versan sobre el tratamiento a los indígenas del nuevo mundo y sobre la guerra justa.

${ }^{39}$ Gómez Robledo, Antonio, El ius cogens internacional, México, UNAM, 1982, p. 14.

${ }^{40}$ CIJ. Case Concernig to Barcelona Traction, Light and Power Company, Belgica vs. España, 1970.

${ }^{41}$ Verdross, Alfred, "Forbidden treaties in international law", American Journal of International Law, núm. 31, 1937, pp. 571 y 572 .

${ }^{42}$ Idem.
} 
Esta revista forma parte del acervo de la Biblioteca Jurídica Virtual del Instituto de Investigaciones Jurídicas de la UNAM

En los años siguientes, la doctrina internacional acogería paulatinamente el concepto de ius cogens. Así, en 1950, Jesús María Yepes afirmaría en la Comisión de Derecho Internacional (CDI), que todo tratado debía tener un objeto y un fin lícito respetando la moral superior que representaba el derecho internacional. ${ }^{44}$ En 1963, fue Humprey Waldock quien presentó en la CDI una propuesta para la codificación del concepto de ius cogens en una Convención sobre el Derecho de los Tratados. ${ }^{45}$ En el debate que siguió a esta propuesta, el comisionado Briggs propuso que no se ejemplificaran las normas de ius cogens para evitar que se pensara que era una lista taxativa o que las nuevas normas imperativas iban a tener una jerarquía menor a las consagradas. ${ }^{46}$ Por su parte, el comisionado Tunkin aportó una visión más positivista, al afirmar que las normas imperativas podrían ser creadas tanto por medios consuetudinarios como por medios convencionales, puesto que su consagración como normas imperativas no obedecía a ninguna ley natural. ${ }^{47}$

En definitiva, como afirma Antonio Gómez, fue a raíz de la propuesta de Waldock que los comisionados aceptaron con gran facilidad la noción de norma imperativa. Quedaba, sin embargo, por determinar su fundamento. Para ello, se avanzaron tres tipos de argumentos. Según las posiciones ius naturalistas, las normas imperativas se derivaban de la naturaleza propia del ser humano, y sólo se podía llegar a ellas a través de la razón. En consecuencia, se trataba de normas únicas e inmutables que protegían valores de vocación universal. ${ }^{48}$

\footnotetext{
${ }^{43}$ Ibidem, p. 574. Esto lleva a nuestro autor a criticar el positivismo, al afirmar que todo orden jurídico positivo tiene sus raíces en la ética de una comunidad, de manera que la norma no puede ser entendida al margen de dichas raíces.

${ }^{44}$ Gómez Robledo, Antonio, El ius cogens internacional, cit., 1982, p. 34.

${ }^{45}$ Ibidem, p. 40.

${ }^{46}$ Ibidem, p. 41.

${ }^{47}$ Ibidem, p.45.

${ }^{48}$ La concepción más pura del ius cogens como normas derivadas del derecho natural implica la existencia de normas básicas de justicia inmanentes a la naturaleza humana. Estas normas han sido desarrolladas en varias oportunidades a través de los siglos, siendo una de sus utilizaciones más notorias la de Jacobo Bossuet, para quien las normas debían estar derivadas de los designios de la providencia divina. Así, para Bossuet, "No hay azar en la marcha de las cosas humanas; la fortuna — esa divinidad ciega de Maquiavelo — "no es más que una palabra que no tiene sentido". La providencia gobierna a los hombres y a los Estados, no de una manera vaga y general, sino de un modo muy particular: verdadero “dirigismo divino”. En Chevallier, Jean-Jaques, Los grandes textos políticos, Madrid, Aguilar Editores, 1980, p. 69. Por su parte, la idea de valores de justicia universal que pueden llegar a condenar conductas como crímenes cometidos contra la humanidad como un todo ha sido desarrollada largamente. Uno de los aportes
} 
Esta revista forma parte del acervo de la Biblioteca Jurídica Virtual del Instituto de Investigaciones Jurídicas de la UNAM

Por su parte, para las posiciones positivistas el ius cogens requería de hechos sociales plasmados en la creación de normas imperativas a través de métodos aceptados como tales por el derecho internacional. De esta manera, las normas imperativas tendrían una naturaleza dinámica y estarían sujetas a cambios derivados de nuevas circunstancias sociales y de nuevas estructuras normativas. ${ }^{49}$

Finalmente, un tercer grupo de posiciones, que compartían con las positivistas la naturaleza dinámica del ius cogens, identificaban este último con el orden público internacional, al que veían como la única limitación para la creación de derecho internacional por parte de los sujetos de tal ordenamiento jurídico. ${ }^{50}$

Estas tres concepciones aparecieron en 1968 y 1969 durante la Conferencia de Viena, al debatirse el texto finalmente propuesto por la CDI, en el que se definían las normas imperativas con base en los siguientes dos elementos objetivos: la imposibilidad de modificación de las normas imperativas por vía de tratados y costumbre internacional que no tuviera el rango de norma imperativa, y la exigencia de una norma de igual valor para su enmienda. Además, mientras la delegación de México afirmó que las normas imperativas tenían que ver con el interés público del

más notables en la materia, antes de la tipificación de los crímenes internacionales en el derecho internacional, es la adoptada por el filósofo Edmund Burke ante el Parlamento británico, donde acusaba a Warren Hastings, comandante de los ejércitos británicos en India oriental, de cometer abusos y crímenes atroces, que para Burke constituían un atentado a la conciencia de la humanidad y al concepto de justicia. En Nimmo, John, The works of the right honourable Edmund Burk, Londres, 1899, vol. X, pp. 144 y 145. La idea de la existencia de una conciencia de la humanidad es el pilar fundamental de las ideas naturalistas modernas que identifican los derechos humanos como parte primordial del orden internacional y a algunas de sus normas como normas imperativas de derecho internacional. Cançado-Trindade, Augusto, La ampliación del contenido material del ius cogens, disponible en http://www.oas.org/dil/esp/3\%20-\%20cancado.DM.MR.1-16.pdf.

49 Algunas posturas doctrinales en la actualidad abogan por la creación de una doctrina fuerte del ius cogens en el marco del sistema de fuentes del derecho internacional, lo que implica la participación activa de la voluntad estatal. D'Amato, Anthony, "Is a bird, is a plane, no is ius cogens ”, Connecticut Journal of International Law, vol.6, núm. 1, otoño de 1990, pp. 1-6. Por su parte, en el derecho penal internacional, autores como Bassioni, identifican la creación de normas imperativas con la práctica de los Estados, lo que implicaría que la derivación de esas normas se haría por un ejercicio volitivo de los actores primarios del derecho internacional, y no como una aplicación de valores naturales superiores. Bassioni, Cheriff, "International crimes: ius cogens and obligatio erga omnes”, Law and Contemporany Problems, vol. 59, núm. 4, 1996, p. 66.

${ }^{50}$ Para un estudio completo del concepto de orden público en la discusión de las normas imperativas: Varón, Antonio, "Orden público internacional y normas ius cogens: una perspectiva desde la Comisión de Derecho Internacional y la Convención de Viena de 1969”, Diálogo de Saberes, vol. 32, fasc. 32, pp. 221 y ss. 
Esta revista forma parte del acervo de la Biblioteca Jurídica Virtual del Instituto de Investigaciones Jurídicas de la UNAM

orden internacional que provenía de la propia condición humana, ${ }^{51}$ otras delegaciones propusieron un tercer elemento en la definición de ius cogens, consistente en el consenso sobre la existencia de tales normas por parte de la comunidad internacional, con el fin de evitar toda subjetividad a la hora de definir las normas imperativas. ${ }^{52}$

La Convención de Viena reconoció, mas no creó, la existencia del ius cogens dentro de las normas del derecho internacional, estableciendo que cualquier tratado que se creara en contravención de dichas normas imperativas sería nulo. ${ }^{53}$ Asimismo, reconoció el carácter dinámico del ius cogens, estableciendo la posibilidad de que estas normas sean modificadas por otras de igual jerarquía. ${ }^{54}$ En la Convención de Viena no se crearon normas imperativas de derecho internacional —de manera que las normas de ius cogens conservan sus efectos independientemente de la suerte que corriera la Convención-, sino que se definieron los elementos que habían de tener dichas normas. Éstos iban a ser los dos originalmente propuestos por la CDI, más la exigencia del consenso en su proceso de formación. ${ }^{55}$ Es importante enfatizar que el ius cogens, en los términos de la Convención de Viena, no constituye una categoría independiente en el sistema de fuentes del derecho internacional. Por el contrario, es una condición de la que se revisten algunas normas emanadas de los tratados y la costumbre internacional.

En consecuencia, como ha subrayado Rafael Casado, las normas de ius cogens "constituyen, sin duda alguna, el más fuerte límite que el medio colectivo en que los Estados viven y desenvuelven su actividad impone al relativismo del derecho

\footnotetext{
${ }^{51}$ Gómez Robledo, Antonio, El ius cogens internacional, cit., p. 58.

52 Ibidem, p. 60.

${ }^{53}$ Así, el artículo 53 de la Convención de Viena sobre el Derecho de los Tratados, de 1969, establece que "Es nulo todo tratado que, en el momento de su celebración, esté en oposición con una norma imperativa de derecho internacional general. Para los efectos de la presente Convención, una norma imperativa de derecho internacional general es una norma aceptada y reconocida por la comunidad internacional de Estados en su conjunto como norma que no admite acuerdo en contrario y que sólo puede ser modificada por una norma ulterior de derecho internacional general que tenga el mismo carácter".

${ }^{54}$ Así, el artículo 64 de la Convención de Viena establece: "Aparición de una nueva norma imperativa de derecho internacional general (jus cogens). Si surge una nueva norma imperativa de derecho internacional general, todo tratado existente que esté en oposición con esa norma se convertirá en nulo y terminará".
}

${ }^{55}$ D’Amato, Anthony, Is a bird, is a plane, no is ius cogens, cit., p. 3. 
Esta revista forma parte del acervo de la Biblioteca Jurídica Virtual del Instituto de Investigaciones Jurídicas de la UNAM

internacional, al voluntarismo y subjetivismo de los Estados soberanos". ${ }^{56} \mathrm{La}$ actuación de los Estados en contravención de las mismas, aunque sea fruto de la adopción de medidas de políticas públicas dirigidas a "facilitar" procesos de transición, da lugar a la responsabilidad internacional del Estado por el hecho internacionalmente ilícito.

\section{Desarrollo del concepto de ius cogens en la práctica internacional}

La práctica internacional posterior a la Convención de Viena ha superado las controversias sobre la existencia del ius cogens para asumirlo como un concepto aceptado, aunque difuso en su ámbito y aplicabilidad. ${ }^{57} \mathrm{~A}$ esta situación ha contribuido la timidez de la Corte Internacional de Justicia a la hora de desarrollar los aspectos concretos de la noción de norma imperativa en el derecho internacional. Sólo en el caso de las Actividades Militares y Paramilitares en y contra Nicaragua, se adentra la CIJ en la calificación de toda una serie de principios (en particular el que prohíbe la agresión), como fundamentales o esenciales para las relaciones internacionales. ${ }^{58}$ Como Remiro Brotons ha subrayado, en el resto de casos la CIJ evita referirse al concepto de ius cogens para limitarse a afirmar el alcance universal de ciertos principios en cuanto que obligaciones erga omnes, esto es, normas de carácter general y vinculante para todos los Estados. ${ }^{59}$

Ante esta situación, han sido los tribunales internacionales penales y los tribunales regionales de protección de derechos humanos los que han profundizado más en el concepto y características de las normas de ius cogens. Así, el TIPY ha definido el concepto de norma imperativa como

...una norma que en la jerarquía internacional tiene un rango superior al derecho de los tratados e incluso a las normas consuetudinarias ordinarias. Las consecuencias más evidentes de este rango superior es que el principio en cuestión no puede ser derogado por los Estados mediante tratados

\footnotetext{
${ }^{56}$ Casado Raigón, Rafael, Notas sobre el ius cogens internacional, Córdoba, 1991, p. 11.

${ }^{57}$ Aust, Anthony, Handbook of international law, 2a. ed., Oxford, Oxford University Press, Kindle Edition, 2007.

${ }^{58}$ CIJ, Military and paramilitary activities in and against Nicaragua (Nicaragua vs. United States of America), Merits, 1986. Para un análisis detallado de los aportes de esta sentencia; Chetail, Vincent, "The contribution of the International Court of Justice to the international humanitarian law”, International Review of the Red Cross, vol. 85, núm. 850, 2003, pp. 235-268.

${ }^{59}$ Brotons, Remiro y otros, Derecho nternacional, cit., p. 69. Refiriendose al asunto de Timor Oriental y al asunto para la Prohibición y Sanción del Delito de Genocidio.
} 
Esta revista forma parte del acervo de la Biblioteca Jurídica Virtual del Instituto de Investigaciones Jurídicas de la UNAM

internacionales o en virtud de costumbres locales o especiales o incluso de normas consuetudinarias generales que no están dotadas de la misma fuerza normativa. $^{60}$

En cuanto al proceso de formación de normas imperativas, la doctrina afirma unánimemente la posibilidad de que éste tenga lugar por vía consuetudinaria. ${ }^{61} \mathrm{Sin}$ embargo, en lo que respecta a su creación por vía de tratados, las opiniones son divergentes. Así, Krystina Marek considera que "el derecho internacional general existe única y exclusivamente como derecho consuetudinario", puesto que éste "se adhiere más íntimamente a la infraestructura que gobierna, es decir que a la larga, corresponde mejor a las necesidades genuinas de comunidad internacional". ${ }^{62}$ En el mismo sentido, Julio Barberis sostiene que hay que diferenciar entre la creación propiamente dicha de normas imperativas y su simple codificación, ${ }^{63}$ de manera que los tratados internacionales sólo serían capaces de codificar las normas imperativas previamente creadas por vía de costumbre. Sin embargo, el propio autor concede que no puede excluirse la posibilidad de que se puedan generar normas imperativas dentro de un tratado del que hicieran parte todos los Estados del mundo. ${ }^{64}$

Por su parte, Antonio Gómez afirma la posibilidad de creación de normas imperativas por vía de un tratado internacional. En su opinión, existen ciertas normas que al momento de recogerse convencionalmente no tenían rango de ius cogens, como es el caso de la prohibición del uso de la fuerza o la libre autodeterminación de los pueblos, y que solamente después de su inclusión en un tratado internacional lograron adquirir la fuerza normativa necesaria para convertirse en normas imperativas.

En lo concerniente al consenso requerido en el proceso de formación de las normas de ius cogens, Ricardo Abello plantea la dificultad de delimitar el conjunto de sujetos de derecho internacional que pueden estar involucrados en el proceso de creación de normas de ius cogens, debido a la dificultad de definir el concepto de

\footnotetext{
${ }^{60}$ ICTY, Prosecutor vs. Anto Furunddja, sentencia del 10 de diciembre de 1998.

${ }^{61}$ Bassioni, Cheriff, "International crimes: ius cogens and obligatio erga omnes”, cit., p. 66.

${ }^{62}$ Marek, Krystina, “Thoughts on codification”, en Gómez Robledo, Antonio, El ius cogens internacional, cit., p. 101.

${ }^{63}$ Barberis, Julio, "La liberté de traiter des Etats et les ius cogens", en Gómez Robledo, Antonio, El ius cogens internacional, cit., p. 101.

${ }^{64}$ Gómez Robledo, Antonio, El ius cogens internacional, cit., p. 101.
} 
Esta revista forma parte del acervo de la Biblioteca Jurídica Virtual del Instituto de Investigaciones Jurídicas de la UNAM

"sociedad internacional en su conjunto". ${ }^{65}$ En particular, afirma este autor, los tribunales internacionales, si bien no participan en el proceso de formación de este tipo de normas, sí juegan una función muy importante en su identificación y reconocimiento. ${ }^{66}$

Finalmente, en lo que hace a su contenido, Markus Petsche considera que el enfoque excesivamente teórico del concepto de ius cogens le ha impedido tener un mayor impacto en la práctica internacional. ${ }^{67}$ En consecuencia, propone una visión del ius cogens desde la perspectiva de los valores que protege, los cuales constituyen el fundamento último del ordenamiento jurídico internacional. ${ }^{68}$

\section{LA NATURALEZA DE IUS COGENSDE LA NORMATIVA QUE REGULA EL FENÓMENO DE LA LESA HUMANIDAD Y SUS EFECTOS JURÍDICOS}

La sección anterior nos ha permitido dilucidar varios elementos en cuanto al contenido y proceso de formación del ius cogens, que procederemos a aplicar en la presente sección, para analizar si la normativa que regula el fenómeno de la lesa humanidad y sus efectos jurídicos tiene tal naturaleza. En cuanto a su contenido, hemos de preguntarnos si el bien jurídico protegido por los crímenes de lesa humanidad forma parte del fundamento último sobre el que se construye el actual ordenamiento jurídico internacional. Con respecto a su proceso de formación, será preciso analizar el grado de consenso mostrado por los miembros de la sociedad internacional respecto a la naturaleza imperativa de la mencionada normativa. Finalmente, al haber sido la jurisprudencia de los tribunales internacionales penales, de los tribunales regionales de protección de derechos humanos y de la propia Corte Internacional de Justicia la que ha desarrollado en gran medida el concepto de ius cogens, tendremos que analizarla debido a su función esencial en la identificación y el reconocimiento de las normas imperativas.

\footnotetext{
${ }^{65}$ Abello, Ricardo, "Introducción al estudio de las normas de ius cogens en la Comisión de Derecho Internacional", Revista Universitas, Bogotá, 2011, p. 91.

${ }^{66}$ Ibidem, p. 96. La pregunta que se desprende de esta posición es si los tribunales regionales con competencia exclusiva para conocer de sistemas jurídicos enmarcados en un marco regional y no universal podrían llegar a identificar normas imperativas dentro de su propio derecho aplicable.

${ }^{67}$ Petsche, Markus, "Jus cogens as a vision of international legal order?", Pennsilvania State International Law Review, núm. 20, 258, 2011.

${ }^{68}$ Idem. Esta posición, afirma el autor, sería coherente con la forma en la que operan los ordenamientos jurídicos de cualquier sociedad humana, puesto que los mismos consagran los valores que constituyen su fundamento último a través de su protección en normas del mayor rango normativo.
} 
Esta revista forma parte del acervo de la Biblioteca Jurídica Virtual del Instituto de Investigaciones Jurídicas de la UNAM

\section{Naturaleza y contenido del bien jurídico protegido en los crímenes de lesa humanidad}

Definir el bien jurídico que la sociedad internacional busca proteger en los crímenes contra la humanidad no es una tarea sencilla, puesto que éstos se caracterizan por la existencia de una multiplicidad de actos graves de violencia ("ataque") sistemática o a gran escala contra la población civil, con la participación o tolerancia del poder político de iure(Estado) o de facto (organización). ${ }^{69}$

Por una parte, cada uno de estos actos de violencia, denominados por algunos autores como hechos individuales, ${ }^{70}$ afecta con particular intensidad a uno o varios intereses esenciales del sujeto pasivo, como sucede con la propia vida, la integridad física, la salud o la libertad. ${ }^{71}$

Por otra parte, la exigencia de que cada hecho individual sea parte de un fenómeno de violencia más amplio contra la población civil, que debe tener ciertas características propias, como la sistematicidad o gran escala, y la intervención del poder político imperante en la región en la que se producen los hechos, hace que nos encontremos ante situaciones en las que los propios cimientos de la sociedad internacional empiezan a tambalear de forma peligrosa. ${ }^{72}$ El preámbulo del ER se refiere a esta situación cuando afirma que los crímenes contra la humanidad constituyen una amenaza para la paz, la seguridad y el bienestar de la humanidad. De ahí que se pueda afirmar que el bien jurídico protegido por los crímenes de lesa

\footnotetext{
${ }^{69}$ Gil Gil, Alicia, "Los crímenes contra la humanidad y el genocidio en el Estatuto de la Corte Penal Internacional a la luz de «los elementos de los crímenes»”, en Ambos, Kai (coord.), La nueva justicia penal supranacional, Valencia, Tirant lo Blanch, 2002, p. 94.

${ }^{70}$ Werle, Gerhard, Tratado de derecho penal internacional, 2a. ed., Valencia, Tirant lo Blanch, 2010, pp. 371 y ss.; Ambos, Kai, La Corte Penal Internacional, Buenos Aires, Rubinzal-Culzoni, 2007, p. 271.

${ }^{71}$ Se trata, en definitiva, de actos que menoscaban de forma particularmente grave alguno de los intereses más preciados de la víctima, que necesita para su autorrealización y el desarrollo de su personalidad en la vida social. De ahí que se pueda afirmar que el carácter sistemático o a gran escala de la violencia en las situaciones de crímenes contra la humanidad no diluye la naturaleza y consecuencias de cada uno de los actos individualmente considerados. Vanegas Moyano, Mauricio, "De los delitos de lesa humanidad y de los delitos contra las personas y bienes protegidos por el derecho internacional humanitario", en Castro, Carlos (coord.), Manual de derecho penal, parte especial, Bogotá, Editorial Universidad del Rosario y Temis, 2011, t. I, pp. 60 y ss.

${ }^{72}$ Se puede afirmar que fue en el Justice Case en el que por primera vez se establece la necesidad de la existencia de un contexto en donde se pueda excluir los delitos aislados. Ambos, Kai, La Corte Penal Internacional, cit., p. 221.
} 
Esta revista forma parte del acervo de la Biblioteca Jurídica Virtual del Instituto de Investigaciones Jurídicas de la UNAM

humanidad forma parte del fundamento último sobre el que se construye el actual ordenamiento jurídico internacional.

En consecuencia, los intereses protegidos por los crímenes contra la humanidad no son exclusivamente individuales, sino que incluyen intereses de la sociedad internacional en su conjunto, ${ }^{73}$ de manera que su titularidad corresponde a toda la humanidad o, lo que es igual, al "hombre colectivo", lo que significa que tienen naturaleza supraindividual. ${ }^{74}$

\section{La jurisprudencia de los tribunales internacionales penales}

Los tribunales internacionales penales han hecho referencia a las normas de ius cogens y, más específicamente, a conductas criminales cuya prohibición ha adquirido tal carácter de norma imperativa. Así, en el caso Tadic, la Sala de Apelaciones del TPIY se refirió expresamente a la sección del informe del secretario general de la Organización de las Naciones Unidas, en la que el secretario subrayaba la facultad del Consejo de Seguridad de adoptar definiciones de los crímenes de competencia del Tribunal, apartándose del derecho internacional consuetudinario, siempre y cuando respetara las normas de ius cogens. ${ }^{75}$

Por su parte, la Sala de Primera Instancia del TPIY en el caso Kupreskic, haciendo referencia a las normas de derecho internacional humanitario, ha afirmado que la prohibición de cometer crímenes de guerra, crímenes de lesa humanidad y genocidio, constituye una norma de ius cogens. El aporte adicional de este pronunciamiento es la consecuencia que deriva de la categorización de estas prohibiciones como normas imperativas. En este sentido, la Sala ha subrayado que no se aplica la regla de suspensión de la aplicación o terminación del tratado por incumplimiento de una obligación por una de las partes, cuando la obligación incumplida está relacionada

\footnotetext{
${ }^{73}$ A este respecto, Luban, David, Una teoría de los crímenes contra la humanidad, Bogotá, Temis, 2011, p. 21, afirma que los crímenes contra la humanidad cumplen con la doble condición de ofender la cualidad de ser humano (humaness) y afectar los intereses de toda la humanidad. Es decir, que hay un ataque al ser humano como entidad individual y al grupo del que es parte como ser social. También Ambos, Kai, "Crímenes de lesa humanidad y la Corte Penal Internacional”, Cuadernos de derecho penal, Bogotá, Universidad Sergio Arboleda, 2013, p. 99.

${ }^{74}$ Para profundizar sobre la evolución del concepto de bienes jurídicos supraindividuales, Castro Cuenca, Carlos Guillermo, "Algunos lineamientos sobre la legitimidad del injusto en los bienes jurídicos supraindividuales", Problemas Actuales de Derecho Penal, Santiago, Ediciones Jurídicas de Santiago, 2006, pp. 81 y ss.

75 TPIY, Appeals Chamber Judgment, Prosecutor vs. Dusko Tadic, Case núm.: IT-94-1-A, 15 de julio de 1999, pfo. 296, citando el reporte del secretario general de las Naciones Unidas en su pfo. 48.
} 
Esta revista forma parte del acervo de la Biblioteca Jurídica Virtual del Instituto de Investigaciones Jurídicas de la UNAM

con la protección del ser humano tratándose de instrumentos de carácter humanitario. ${ }^{76}$

En relación con lo anterior, el TPIY se ha referido específicamente al crimen de tortura. A pesar de esto, el Tribunal ha utilizado el derecho internacional de los derechos humanos para ampliar la categoría de crímenes de lesa humanidad a conductas como la desaparición forzada, por lo que también se aplicarían las reglas que se desarrollarían. ${ }^{77}$ Así, el TPIY se pronunció por primera vez en este sentido en el caso Delalic et al., en el que la Sala de Primera Instancia, refiriéndose a la prohibición de la tortura y citando al relator especial de las Naciones Unidas contra esta conducta, afirmó el carácter de ius cogens de dicha prohibición. ${ }^{78}$

Un mes más tarde, en diciembre de 1998, la Sala de Primera Instancia II del mismo Tribunal en el caso Furundzija, se pronunció nuevamente en relación con la prohibición de la tortura como norma de ius cogens, pero esta vez con mayor análisis. Así, además de reiterar el carácter alcanzado por esta prohibición, afirmó que éste surge por "la importancia de los valores que protege" ${ }^{\text {"79 }}$ dicha prohibición. Acto seguido, pasó a indicar el impacto y efectos que se generan a partir de tal categorización de la prohibición de la tortura. En primera medida, indicó que el ser una norma de ius cogens implica que tal prohibición "se ha convertido en uno de los estándares fundamentales de la comunidad internacional". ${ }^{80}$ Asimismo, la Sala de Primera Instancia II consideró que esto produce un efecto disuasivo en cuanto a la comisión de la tortura porque envía el mensaje de estar frente a una prohibición absoluta.

\footnotetext{
${ }^{76}$ TPIY, Trial Chamber Judgment, Prosecutor vs. Zoran Kupreskic, Mirjan Kupreskic, Vlatko Kupreskic, Drogan Papic, Case núm. IT-95-16-T, 14 de enero de 2000, pfo. 520.

77 TPIY, Trial Chamber Judgment, Prosecutor vs. Kvocka, Case núm. I-98-30/1-T, 2 de noviembre de 2001, pfo. 208.

${ }^{78}$ TPIY, Trial Chamber Judgment, Prosecutor vs. Zejnil Delalic, Zdravko Mucic, Hazim Delic, Esad Landzo, Case núm. IT-96-21-T, 16 de noviembre de 1998, párrafo 454. Tres años más tarde, esta posición fue reiterada por la Sala de Primera Instancia II en el caso Kunarac et al., citando precisamente el caso Delalic et al. Véase Tribunal Penal Internacional para la Antigua Yugoslavia, Trial Chamber Judgment, Prosecutor vs. Dragoljub Kunarac, Radomir Kovac, Zoran Vokovic, Case núm. IT-96-23-T \& IT-96-23/1-T, 22 de febrero de 2001, párrafo 466.

79 TPIY, Trial Chamber Judgment, Prosecutor v. Anto Furundzija, Case núm. IT-95-/7/1-T, 10 de diciembre de 1998, párrafo 153 .

${ }^{80}$ Ibidem, pfo. 154.
} 
Esta revista forma parte del acervo de la Biblioteca Jurídica Virtual del Instituto de Investigaciones Jurídicas de la UNAM

La Sala enfatizó los efectos que se generan tanto a nivel interestatal como a nivel individual, por pertenecer la prohibición de la tortura al ius cogens. En cuanto a los primeros, resaltó la deslegitimación que se hace desde el nivel internacional, "a cualquier acto administrativo, legislativo o judicial" que autorice la tortura. Esto abarca las leyes de amnistía que "autoricen, condonen o absuelvan a los perpetradores de una tortura", ${ }^{81}$ así como la posibilidad de que las víctimas inicien un procedimiento ante órganos judiciales tanto nacionales como internacionales encaminados a que se declare la ilegalidad de la medida desde el punto de vista internacional, o incluso a obtener una decisión favorable en una demanda de tipo civil ante una corte extranjera por los daños ocasionados en virtud de la conducta o medida contraria a esta prohibición de ius cogens.

En lo que respecta al nivel individual, esto es, a la responsabilidad penal, la Sala recordó que "cada Estado tiene el derecho de investigar, perseguir y castigar o extraditar individuos acusados de tortura que se encuentren en territorio bajo su jurisdicción". ${ }^{82}$ Además, afirmó la aplicación de la jurisdicción universal derivada del carácter universal del crimen. ${ }^{83}$ La Sala mencionó también la imprescriptibilidad del crimen y la imposibilidad de considerarlo un delito político o conexo como excepción para la procedencia de la extradición, como consecuencias adicionales derivadas del carácter de ius cogens de la prohibición de torturar. ${ }^{84}$

Con posterioridad, la salas de Apelaciones y Primera Instancia del TPIY en los casos Celebic ${ }^{85}$, Naletilic y Martinovic ${ }^{86}$, y Simic, $^{87}$ han afirmado expresamente el

\footnotetext{
${ }^{81}$ Ibidem, pfo. 155.

${ }^{82}$ Ibidem, pfo. 156.

${ }^{83}$ En este punto la Sala cita a la Corte Suprema de Justicia de Israel en el caso Eichmann, citado a su vez por una corte del circuito sexto de Estados Unidos en el caso Demjanjuk de 1985.
}

${ }^{84}$ Ibidem, párrafo 157.

85 TPIY, Appeals Chamber Judgment, Prosecutor vs. Zejnil DELALIC, Zdravko MUCIC (aka "PAVO”), Hazim DELIC and Esad LANDŽO (aka “ZENGA”), (“Celebici Case”), case núm. IT-96-21-A, 20 de febrero de 2001, pie de página 225,

86 TPIY, Trial Chamber Judgment, Prosecutor vs. Mladen NALETILIC, aka "TUTA" and Vinko MARTINOVIC, aka “ŠTELA”, case núm. IT-98-34-T, 31 de marzo de 2003, párrafo 336, citando Celebici case, Trial Chamber Judgment, párrafo 454.

87 TPIY, Trial Chamber Judgment, Prosecutor vs. MILAN SIMIĆ, case núm. IT-95-9/2-S, 17 de octubre de 2002, pfo. 34 . 
Esta revista forma parte del acervo de la Biblioteca Jurídica Virtual del Instituto de Investigaciones Jurídicas de la UNAM

carácter de ius cogens que tiene la prohibición de la tortura. Asimismo, la Sala de Apelaciones del Tribunal Especial para Sierra Leona en el caso Gbao se refiere a la mencionada sentencia en el caso Furundzija en lo relativo a la prohibición de la tortura como norma de ius cogens. ${ }^{88}$

En consecuencia, se puede afirmar que si bien el aporte de los tribunales internacionales penales es significativo, éste es más limitado que el realizado por la Corte Interamericana de Derechos Humanos; no sólo en cuanto al número de pronunciamientos, sino en cuanto a las conductas respecto a las que se ha referido la pertenencia a esta categoría de normas, como se verá a continuación.

\section{La jurisprudencia de la Corte Interamericana de Derechos Humanos}

Si bien la Corte IDH no es un tribunal internacional penal, por la naturaleza de las violaciones a derechos humanos sobre las que tiene competencia ha tenido la oportunidad de pronunciarse en varios casos en los que las violaciones alegadas se produjeron como parte de un ataque sistemático o generalizado contra la población civil en ejecución de la política de un gobierno.

Esta situación se planteó, en particular, en el caso Almonacid Arellano y otros vs. Chile, relativo a la represión política que siguió al golpe de Estado dado por el general Augusto Pinochet en Chile en 1973, y que ocasionó la detención, tortura, desaparición y muerte de cientos de personas por las fuerzas armadas chilenas, entre las que se encontraba el señor Luis Alfredo Almonacid Arellanúm. En su decisión de fondo de 2006, la Corte IDH no sólo indica que se encuentra en presencia de crímenes de lesa humanidad, sino que además afirma que para 1973, la comisión de estos crímenes era violatoria del ius cogens, por cuanto la prohibición de cometerlos tenía tal naturaleza. ${ }^{89}$

Además, para la Corte IDH, esta naturaleza de ius cogens se extiende también a las normas que afirman la imprescriptibilidad de dicha responsabilidad penal, y que prohíben las leyes de amnistía, de manera que su contenido no puede ser alterado por vía convencional, y es aplicable y exigible a todo Estado en razón a su naturaleza

\footnotetext{
${ }^{88}$ Tribunal Especial de Sierra Leona, Appeals Chamber, Decision on Preliminary motion on the invalidity of the agreement between the United Nations and the Government of Sierra Leone on the establishment of the Special Court, Prosecutor vs. Augustine Gbao, case núm. SCSL-2004-15-AR72 (E), 25 de mayo de 2004, pfo. 9.

${ }^{89}$ Corte IDH, caso Almonacid Arellano y otros vs. Chile. Excepciones preliminares, fondo, reparaciones y costas, sentencia de 26 de septiembre de 2006, serie C, núm. 154, párrafo 99.
} 
Esta revista forma parte del acervo de la Biblioteca Jurídica Virtual del Instituto de Investigaciones Jurídicas de la UNAM

de normas imperativas..$^{90}$ En particular, la Corte IDH afirmó que si la prohibición de una conducta y su correspondiente responsabilidad penal constituyen normas de ius cogens, la misma naturaleza han de tener las normas que recogen la obligación de los Estados de realizar dicha responsabilidad mediante la investigación de los hechos, el enjuiciamiento de los presuntos responsables y la ejecución de las penas que se les impongan. $^{91}$

En las decisiones de fondo de los casos Penal Miguel Castro Castro (2005) ${ }^{92}$ y La Cantuta (2006), ${ }^{93}$ ambos relativos a la represión por agentes estatales durante la presidencia de Alberto Fujimori en Perú entre 1992 y 2001, la CIDH ha afirmado el carácter de ius cogens de la normativa que prohíbe los crímenes de lesa humanidad, atribuye responsabilidad internacional penal a quienes incurren en dichos crímenes, afirma la imprescriptibilidad de tal responsabilidad y prohíbe las leyes de amnistía.

Por su parte, la Corte IDH ha subrayado también de manera reiterada en decenas de casos contenciosos la naturaleza de ius cogens de las normas internacionales que prohíben las ejecuciones extrajudiciales, ${ }^{94}$ la tortura, ${ }^{95}$ otras penas o tratos crueles,

${ }^{90}$ Ibidem, pfos. 114 y 153.

${ }^{91}$ Ibidem, pfo. 114. El juez Cançado Trindade había desarrollado previamente esta posición en su voto concurrente en la Opinión Consultiva 18/03. En la misma, después de clarificar que no toda obligación de alcance universal (erga omnes) implica a su vez una obligación de ius cogens, pero sí que toda obligación de ius cogens será siempre una obligación de alcance universal, subraya la naturaleza de ius cogens de la obligación de protección (lo que incluye los deberes de investigación y sanción) frente a aquellas conductas prohibidas en normas de ius cogens. Además, añade el juez Cançado Trindade, dicha obligación de protección tiene una doble dimensión: una horizontal, que se impone en la comunidad internacional en su conjunto, y otra vertical, que incumbe al Estado frente a las personas que se encuentran sometidas a su jurisdicción. Corte Interamericana de Derechos Humanos, Opinión Consultiva OC-18/03 del 17 de septiembre de 2004, solicitada por los Estados Unidos Mexicanos. Condición jurídica y derechos de los migrantes indocumentados, voto concurrente juez A. A. Cançado Trindade, pp. 1-36.

92 Corte IDH, caso penal Miguel Castro Castro vs. Perú, sentencia del 25 de noviembre de 2006, serie C, núm. 160, párrafos 402 y 404.

93 Corte IDH, caso La Cantuta vs. Perú, fondo, reparaciones y costas, sentencia del 29 de noviembre de 2006, serie C, núm. 162, pfos. 168 y 225.

${ }^{94}$ En el caso Villagrán Morales y otros vs. Guatemala, si bien la Corte IDH expresamente no refiere la prohibición de las ejecuciones extrajudiciales como una norma de ius cogens, los jueces Cançado Trindade y Abreu Burelli, en su voto concurrente conjunto, afirman en el contexto de este caso (donde un oficial de la policía y un exoficial de la misma entidad dieron muerte a cinco niños que vivían en las calles de Guatemala), que el derecho a la "vida pertenece al dominio del jus cogens". Dos años después, en la decisión de fondo del caso Barrios Altos vs. Perú (donde además de existir un contexto de ejecuciones extrajudiciales, se promulgan por el Estado unas leyes de autoamnistía para los presuntos responsables de los crímenes cometidos el 3 de noviembre de 1991 en el barrio 
"Barrios Altos" en Lima), nuevamente es a través del voto concurrente del juez Cançado Trindade, que se manifiesta de manera expresa el carácter de ius cogens del derecho a la vida, al afirmar que las leyes de autoamnistía en este caso desconocen "derechos no derogables" (como el de la vida) "que recaen en el ámbito del jus cogens". Además, en el párrafo 41 de la decisión de fondo en este mismo caso, la Corte IDH, al abordar el estudio de la incompatibilidad de estas leyes con la Convención Americana, afirmó que, entre otras conductas, "las ejecuciones sumarias, extralegales o arbitrarias (contravienen) derechos inderogables reconocidos por el derecho internacional de los derechos humanos". En este contexto, si bien expresamente no se hace mención al concepto de ius cogens, la calificación "inderogable" respecto a normas reconocidas como tales por el derecho internacional de los derechos humanos, debe entenderse como una referencia a una norma de ius cogens, que en este caso sería el derecho a la vida. A partir de 2004, la Corte IDH relaciona expresamente las ejecuciones extrajudiciales con acciones violatorias de normas de ius cogens. Así, la Corte IDH se pronuncia en este sentido, en distintos contextos como son operaciones en supuesta lucha contrainsurgencia en conflictos armados internos, operaciones contra la delincuencia organizada en estados de conmoción interior y, en general, en operaciones encubiertas. Al primer grupo pertenecen los casos Gómez Paquiyauri (2004), Penal Miguel Castro Castro (2006) y La Cantuta (2006), todos ellos contra Perú, donde el Estado es declarado internacionalmente responsable por violaciones a derechos y obligaciones consagradas en la Convención Americana de Derechos Humanos, dentro de un contexto de prácticas sistemáticas de violaciones graves de derechos humanos ocurridas en el Estado en adelanto de supuestas operaciones contrainsurgentes. En dichas operaciones se cometieron, entre otras conductas, "ejecuciones extrajudiciales de personas sospechosas de pertenecer a grupos armados realizadas por agentes estatales siguiendo órdenes de jefes militares y policiales...”. La Corte IDH en los dos primeros casos, y el juez Cançado Trindade en su voto razonado en el tercer caso, subrayan que estas conductas infringen el ius cogens internacional. Gómez Paquiyauri, p. 76. Penal Miguel Castro Castro, p. 203; La Cantuta, voto razonado Cançado p. 54. En el segundo escenario, se encuentra el caso Zambrano Vélez vs. Ecuador (2007), en el que la Corte IDH estudia las violaciones a la Convención Americana cometidas por miembros de las fuerzas armadas y la policía nacional, al matar extrajudicialmente a tres personas en el marco de un estado de emergencia decretado en 1992 por "grave conmoción interna”. En la página 96 de su decisión de fondo, la Corte IDH afirma que "sin importar las condiciones de cada Estado, existe una prohibición absoluta... de las ejecuciones sumarias y extrajudiciales ... que constituye una norma inderogable de derecho internacional”. El caso Huilca Tecse vs. Perú (2005), también se refiere a una ejecución extrajudicial bajo operaciones encubiertas impulsadas o toleradas por el Estado. En su decisión de fondo, la Corte IDH afirma en la página 65 el desconocimiento del ius cogens mediante la perpetración de esta conducta, en un contexto o "patrón de violaciones de derechos humanos".

${ }^{95}$ En sus primeras aproximaciones al tema, la Corte IDH no fue tan enfática y acudió a otras expresiones para referirse a dicha prohibición. Así, en la página 95 de su decisión de fondo en el caso Cantoral Benavides vs. Perú (2000), hizo referencia a una "prohibición absoluta de la tortura", basándose en un pronunciamiento de la Corte Europea de Derechos Humanos. Posteriormente, en sus decisiones de fondo en los casos García Asto y Ramírez Rojas vs. Perú de 2005 (p. 222), Caesar vs. Trinidad y Tobago de 2005 (p. 59), y Zambrano Vélez y otros vs. Ecuador de 2007 (p. 96) podemos encontrar referencias a la prohibición a la tortura como una norma absoluta e inderogable, o como una conducta "prohibida por contravenir derechos inderogables reconocidos por el derecho internacional de los derechos humanos", como se afirmó en el caso Barrios Altos vs. Perú (2001). Sin embargo, en la actualidad la Corte IDH reconoce la naturaleza de ius cogens de la normativa que prohíbe la tortura y atribuye responsabilidad internacional penal por su comisión. A este respecto, los casos de Maritza Urrutia vs. Guatemala de 2003, p. 92; Hermanos Gómez Paquiyauri vs. Perú de 2004; Tibi vs. Ecuador de 2004; Lori Berenson vs. Perú de 2006; Baldeón García vs. Perú de 2006; Almonacid Arrellano y otros vs. Chile de 2006; Goiburu y otros vs. Paraguay de 2006; Penal Miguel Castro Castro vs. Perú de 2006; La Cantuta vs. Perú de 2006; la Rochela vs. Colombia de 2007; Bueno 


\section{inhumanos o degradantes, ${ }^{96}$ las desapariciones forzadas ${ }^{97}$ y la esclavitud, ${ }^{98}$ incluso cuando estas conductas se cometen de manera aislada y no como parte de un ataque}

Alves vs. Argentina de 2007; González y otras vs. México de 2009; Cabrera García y Montiel Flores vs. México de 2010; Fleury y otros vs. Haití de 2011; El Mozote y lugares aledaños vs. El Salvador de 2012, y Mendoza y otros vs. Argentina de 2013. El pronunciamiento de la Corte en el caso Caesar es de particular interés, teniendo en cuenta que en este caso expresamente se afirman como normas de ius cogens aquellas que prohíben los tratos inhumanos o degradantes, mas no expresamente la prohibición a la tortura como una norma que haya adquirido tal categoría.

96 Inicialmente en el caso Benavidez vs. Perú (2000), la Corte IDH se había referido a esta prohibición no expresamente como de ius cogens sino de carácter absoluto. Sin embargo, en casos posteriores la Corte IDH ha afirmado que, además de la tortura, se considera a las penas o tratos crueles, inhumanos o degradantes, como pertenecientes "hoy día al dominio del ius cogens". Decisiones de fondo en los casos Caesar vs. Trinidad y Tobago (párrafo 100), Ximenes Lopes vs. Brasil (párrafo 126), Servellón García y otros vs. Honduras (párrafo 97), Familia Barrios vs. Venezuela (párrafo 50), y El Mozote y lugares aledaños vs. El Salvador (párrafo 147).

${ }^{97}$ Desde sus inicios Velásquez Rodríguez (1988) Fairén Garbi y Solís Corrales (1989) y Godínez Cruz (1989) todos contra Honduras) hasta hoy (Masacres de Río Negro vs. Guatemala (2012) y Osorio Rivera y Familiares vs. Perú (2013), la Corte IDH ha conocido de casos en los que el fenómeno de las desapariciones forzadas ha estado presente en la región, en particular en contextos de lucha contrainsurgente. Así, las operaciones contra grupos armados al margen de la ley en el Perú — Sendero Luminoso y el Movimiento Revolucionario Túpac Amaru—, desde la década de los ochenta hasta finales de 2000, donde agentes estatales cometieron de manera sistemática violaciones a derechos humanos. Igualmente, las operaciones del ejército de Brasil encaminadas a terminar con el grupo guerrillero do Araguaia, de 1972 a 1975, a través de las cuales el ejército llevó a cabo también conductas violatorias de derechos humanos de la población civil. Véase casos como La Cantuta (2006), Osorio Rivera y Familiares (2013), ambos contra Perú, y Gomes Lund y otro vs. Brasil (2010). Durante el conflicto armado interno que sufrió Guatemala entre los años de 1960 y 1996, también se llevaron a cabo desapariciones forzadas como consecuencia de una práctica sistemática del Estado en la lucha contra miembros de la insurgencia y aquellas personas que, de acuerdo con el Estado, eran catalogados como proclives a ella. Véase casos como Chitay Nech y otros (2010), Gudiel Álvarez y otros (2012), García y Familiares (2012) evidencian esta práctica sistemática en Guatemala. Igualmente, en sistemas de opresión y persecución a la oposición durante dictaduras y periodos oscuros en América Latina, el fenómeno de la desaparición forzada como parte de un patrón implementado por el Estado, se vivió en las décadas de los sesenta y setenta con la "guerra sucia" en México, la política de "tierra arrasada" contra el pueblo maya en Guatemala (19811983), y la "operación cóndor" en las décadas de los setenta y ochenta, que unió a los gobiernos, ejércitos, fuerzas policiales y agencias de inteligencia de los Estados del cono sur americano para implementar dicho sistema de opresión. Véase al respecto Radilla Pacheco vs. México (2009), Masacres de Río Negro vs. Guatemala (2012), Goiburu y otros vs. Paraguay (2006) y Gelman vs. Uruguay (2011). Desde su decisión de fondo en el caso La Cantuta (párrafo 157), la Corte IDH ha afirmado que las normas que prohíben la desaparición forzada y generan responsabilidad internacional penal para quienes incurren en la misma tienen rango de ius cogens. Véase también decisiones de fondo en los casos Osorio Rivera y Familiares (párrafo 112), Gomes Lund y otros vs. Brasil (párrafo 105); Chitay Nech y otros (párrafo 86), Gudiel Álvarez y otros vs. Guatemala (párrafo 92), García y Familiares vs. Guatemala (párrafo 96), Radilla Pacheco vs. México (párrafo 139), Masacres de Río Negro vs. Guatemala (párrafo 114), Goiburu y otros vs. Paraguay (párrafos 84, 93 y 128), y Gelman vs. Uruguay (párrafo 99).

${ }^{98}$ En 1993, la Corte IDH en la sentencia de reparaciones y costas del caso Aloeboetoe y otro vs. Surinam (párrafo 57), afirmó la nulidad de un tratado de esclavitud por desconocer normas de ius cogens. De esta manera, y aunque sin 
Esta revista forma parte del acervo de la Biblioteca Jurídica Virtual del Instituto de Investigaciones Jurídicas de la UNAM

sistemático o generalizado dirigido contra la población civil. Los casos Barrios Altos, Goiburu, Vargas Areco, Almonacid Arellano, Penal Miguel Castro Castro, La Cantuta, Ibsen Cárdenas e Ibsen Peña, Chitay Nech, Gomes Lund, Gelman, Masacre de El Mozote y Masacres de Río Negro, son claros ejemplos de esta tendencia. ${ }^{99}$

En los últimos dos años se han observado ciertos movimientos revisionistas que se encuentran en contradicción con la jurisprudencia consolidada de la Corte IDH, así como con el tratamiento que el derecho internacional ha venido dispensado al fenómeno de la lesa humanidad desde hace décadas. Entre ellos destaca en particular el voto concurrente del expresidente de la Corte IDH, Diego García Sayán, en una decisión de fondo en el caso de la Masacre del Mozote vs. El Salvador, en el que afirma la necesidad de realizar un juicio de ponderación entre los intereses de la paz y los intereses de la justicia, para aquellos crímenes de lesa humanidad ocurridos en conflictos armados no internacionales. ${ }^{100}$ Esta posición es fundamentada en el artículo 6.5 del Protocolo Adicional II, que afirma que “[a] la cesación de las hostilidades, las autoridades en el poder procurarán conceder la amnistía más amplia posible a las personas que hayan tomado parte en el conflicto armado o que se encuentren privadas de libertad, internadas o detenidas por motivos relacionados con el conflicto armado".

Los otros seis jueces de la Corte IDH respondieron al juez García Sayán en la propia decisión de fondo, al recordar que si bien dicha disposición es aplicable en

basarse en jurisprudencia internacional, reiteró lo establecido por la Corte Internacional de Justicia, hacía ya dos décadas en el caso Barcelona Traction, en relación con el carácter imperativo que había adquirido la prohibición de dicha conducta. En aplicación del artículo 64 de la Convención de Viena sobre el Derecho de los Tratados de 1969, la Corte IDH afirmó que un tratado es nulo cuando contiene una disposición contraria a una nueva norma de ius cogens. Si bien en la fecha en la que se celebró el tratado relativo a la esclavitud entre el Reino de los Países Bajos y Surinam (1762), esta conducta no estaba siquiera prohibida por el derecho internacional, para el momento en que la Corte IDH se pronuncia sobre el tema (1991 fondo y 1993 reparaciones y costas), ya había surgido dicha prohibición como norma imperativa, reconociendo así la Corte IDH la existencia de reglas de jus cogens superveniens.

99 Corte IDH, caso Barrios Altos vs. Perú, cit., pfo. 41; caso Almonacid Arellano y otros vs. Chile, cit., pfo. 114; caso La Cantuta vs. Perú, fondo, reparaciones y costas, sentencia del 29 de noviembre de 2006, serie C, núm. 162, pfo. 168; caso Gomes Lund y otros (Guerrilha do Araguaia) vs. Brasil, excepciones preliminares, fondo, reparaciones y costas, sentencia del 24 de noviembre de 2010, serie C, núm. 209, pfo. 147; caso Gelman vs. Uruguay, fondo y reparaciones, sentencia del 24 de febrero de 2011, serie C, núm. 221, pfos. 225-229 y 232; caso Masacres de El Mozote y lugares aledaños vs. El Salvador, fondo, reparaciones y costas, sentencia del 25 de octubre de 2012, serie C, núm. 252, pfo. 286.

${ }^{100}$ Corte IDH, caso Masacres de El Mozote y lugares aledaños vs. El Salvador, cit., voto concurrente del juez Diego García-Sayán, pfos. 20-40. 
Esta revista forma parte del acervo de la Biblioteca Jurídica Virtual del Instituto de Investigaciones Jurídicas de la UNAM

relación con delitos ordinarios cometidos en conflictos armados no internacionales, su ámbito de aplicación no puede extenderse a delitos internacionales de ius cogens, como los crímenes de guerra o de lesa humanidad. En consecuencia, la mayoría de la Corte IDH concluyó:

Por consiguiente, puede entenderse que el artículo 6.5 del Protocolo II adicional está referido a amnistías amplias respecto de quienes hayan participado en el conflicto armado no internacional o se encuentren privados de libertad por razones relacionadas con el conflicto armado, siempre que no se trate de hechos que, como los del presente caso, cabrían en la categoría de crímenes de guerra e, incluso, en la de crímenes contra la humanidad. ${ }^{101}$

Distinta entendemos es la situación planteada en las decisiones de fondo de 2012 en los casos Gudiel Álvarez y otros, y García y Familiares, ambos contra Guatemala. En estas decisiones, la Corte IDH, al referirse a las obligaciones derivadas de la comisión de una conducta prohibida por el ius cogens, indica que "la correlativa obligación de investigar y en su caso enjuiciar y sancionar a sus responsables, adquiere particular intensidad e importancia ante la gravedad de los delitos cometidos y la naturaleza de los derechos lesionados". ${ }^{102}$

Una interpretación estrictamente literal de este pasaje, sin tener en cuenta la jurisprudencia consolidada en la materia de la Corte IDH, podría hacer que algunos pudieran ver ciertos indicios de una presunta negación del carácter de ius cogens a la norma que impone al Estado la obligación de realizar la responsabilidad penal derivada del delito de desaparición forzada. Sin embargo, aunque la fórmula utilizada por la Corte IDH no fue la más afortunada, lo cierto es que cuando se lee a la luz de su consolidada jurisprudencia no cabe sino rechazar esta posible interpretación. Esta conclusión se ve reforzada por la expresa afirmación del carácter imperativo de dicha obligación en la subsiguiente decisión de fondo de la propia Corte IDH en el caso García Lucero y otros vs. Chile (2013), ${ }^{103}$ también relativo a un delito de desaparición forzada.

4. La jurisprudencia de la Corte Internacional de Justicia y de la Corte Europea de Derechos Humanos

\footnotetext{
${ }^{101}$ Corte IDH, caso Masacres de El Mozote y lugares aledaños vs. El Salvador, cit., pfo. 285.

${ }^{102}$ Gudiel Álvarez y otros vs. Guatemala (pfo. 232); García y Familiares, vs. Guatemala (pfo. 131).

103 García Lucero y otros vs. Chile (pfo. 123).
} 
Esta revista forma parte del acervo de la Biblioteca Jurídica Virtual del Instituto de Investigaciones Jurídicas de la UNAM

A diferencia de la Corte Interamericana de Derechos Humanos, la jurisprudencia de la Corte Internacional de Justicia y de la Corte Europea de Derechos Humanos ha sido bastante tímida a la hora de reconocer las obligaciones de los Estados en materia de investigación, juzgamiento y sanción de crímenes internacionales, y en especial de los crímenes de lesa humanidad. Esto se ha debido a que ambas cortes han abordado las normas de ius cogens y su relación con los crímenes de lesa humanidad desde la perspectiva de la colisión de estas normas con el principio de inmunidad de jurisdicción de los Estados.

En su decisión de fondo en el caso de la Orden de Arresto (2002), entre la República Democrática del Congo y Bélgica, la CIJ acogió la posición de la RDC, que sostenía que al ser el acusado de crímenes de lesa humanidad y de guerra su ministro de Relaciones Exteriores, éste se encontraba amparado por la inmunidad personal, que por razón del cargo ejercido reconoce el derecho internacional consuetudinario, con independencia de la naturaleza ordinaria o internacional de los delitos imputados. ${ }^{104}$ Posteriormente, en 2012, la CIJ aceptó las alegaciones de Alemania a favor de su inmunidad de jurisdicción frente a los procesos por daños civiles que se llevaban a cabo en su contra en Italia, con el fin de declarar su responsabilidad como Estado, en la comisión de crímenes internacionales en el marco de la Segunda Guerra Mundial. ${ }^{105}$

Por su parte, la Corte EDH, en el caso Aladsani (2001), ${ }^{106}$ después de aceptar la jurisprudencia del TPIY, que afirma que la prohibición de la tortura es una norma

\footnotetext{
${ }^{104}$ El caso versa sobre una orden de arresto emitida por las autoridades belgas en contra del ministro de Relaciones Exteriores de la República Democrática del Congo por su participación en la comisión de crímenes de lesa humanidad y de guerra. Véase CIJ, Arrest Warrant Case (Democratic Republic of Congo vs. Belgium), sentencia del 14 de febrero de 2002, párrafo 59.

${ }^{105}$ Italia alegó por su parte que la inmunidad de jurisdicción no operaba al tratarse de violaciones a las normas imperativas del derecho internacional ocurridas en territorio italiano, de manera que la inmunidad estatal debía ceder frente al ius cogens. Sin embargo, la CIJ desechó los argumentos de Italia al afirmar la consolidación en el derecho internacional consuetudinario de la norma que reconoce la inmunidad de jurisdicción de los Estados, sin que la naturaleza de la norma presuntamente infringida constituya, conforme al propio derecho internacional consuetudinario, una excepción a la misma. Véase CIJ, Jurisdiction Inmunities of the State Case (Germany vs. Italy). Sentencia del 3 de febrero de 2012, párrafo 62, 88-89, 92.

${ }^{106}$ En 1991, el señor Al-Aladsani, ciudadano del Reino Unido y de Kuwait, acudió a servir como piloto en las fuerzas armadas de este último Estado. Durante su permanencia en el país, algunos videos sexuales que involucraban a un jeque familiar del emir de Kuwait llegaron al poder del peticionario. De alguna manera, estos videos vieron la luz pública. Esta situación generó que en dos ocasiones diferentes, después de terminada la guerra, el jeque y algunos hombres más raptaran al peticionario y lo torturaran durante varios días. Después de su segunda liberación, el señor
} 
Esta revista forma parte del acervo de la Biblioteca Jurídica Virtual del Instituto de Investigaciones Jurídicas de la UNAM

imperativa del derecho internacional, ${ }^{107}$ y una vez analizadas las decisiones del caso del ex dictador chileno, Augusto Pinochet, y las enmiendas a la Foreign Sovereign Immunities Act (FSIA) de Estados Unidos, afirmó que el derecho internacional vigente en 2001 no recogía ninguna excepción a la inmunidad de jurisdicción para casos de graves violaciones de derechos humanos. ${ }^{108}$ Esta posición se ha visto confirmada en 2014 con el fallo del caso Jones and others vs. Reino Unido, en el que la Corte EDH reitera que no existe ninguna norma de derecho internacional consuetudinario que exceptúe la inmunidad de jurisdicción frente a hechos que configuren violaciones al derecho internacional imperativo. ${ }^{109}$ De hecho, para la Corte EDH no existe ningún conflicto entre las normas que regulan la inmunidad de jurisdicción y aquellas que recogen la prohibición de la tortura como norma de ius cogens, porque las primeras tienen una naturaleza meramente procesal en relación con el ejercicio de la jurisdicción para investigar y sancionar los actos de tortura, mientras que la prohibición de la tortura tiene un carácter sustantivo, al establecer una prohibición de carácter imperativo en el derecho internacional.

\section{LA NATURALEZA NO IMPERATIVA DEL CONCEPTO DE JUSTICIA DE TRANSICIÓN}

Las teorías críticas dominantes sobre la justicia relacionan el concepto de justicia con normas de conducta de los seres humanos, o principios orientadores de su conducta, de manera que todo aquello que escape a la conducta del ser humano no es susceptible de ser considerado justo o injusto. ${ }^{110}$ En cuanto a la determinación de lo justo e injusto, Amartya Sen subraya que no puede hacerse a través de ideas preconcebidas que carecen de sustento suficiente para llegar a una respuesta, sino que es necesario llevar a cabo un ejercicio racional complejo en el que entren en juego diferentes tipos de dinámicas argumentativas. Esto no impide, sin embargo,

\footnotetext{
Aladsani regresó al Reino Unido para ser tratado por diferentes quemaduras y daños sicológicos derivados de la tortura recibida. Al regresar al Reino Unido, el peticionario presentó una serie de acciones de tipo civil en contra del jeque y el Estado de Kuwait; sin embargo, todas ellas fueron rechazadas en virtud del principio de inmunidad estatal.

${ }^{107}$ Corte EDH, caso Aladsani vs. Reino Unido, sentencia de noviembre 21 de 2011, pfos. 59 y 60.

${ }^{108}$ Ibidem, párrafo 66.

${ }^{109}$ Corte EDH, caso Jones y otros vs. Reino Unido, sentencia del 14 de enero de 2014, pfo. 79.

${ }^{110}$ Gheaus, Anca, "The feasibility constraint on the concept of justice the feasibility constraint on the concept of justice", Philosophical Quarterly, vol. 63, núm. 252, julio, 2013, p. 446.
} 
Esta revista forma parte del acervo de la Biblioteca Jurídica Virtual del Instituto de Investigaciones Jurídicas de la UNAM

afirmar la dificultad inmanente de la consecución de consensos para determinar lo justo o lo injusto. ${ }^{111}$

En este contexto, el concepto de "justicia de transición" es definido por algunos autores $^{112}$ como el conjunto de intentos o procesos de una sociedad para superar situaciones de abusos cometidos a gran escala, con el fin de identificar a los responsables y contribuir al proceso de reconciliación. ${ }^{113}$

Para estos autores, de lo que se trata en última instancia es de adoptar, en aras de facilitar los procesos de transición, un conjunto de medidas de política pública en el ámbito de la determinación de la verdad, el establecimiento y la realización de responsabilidades individuales y la reparación a las víctimas, dirigidas a reducir significativamente el contenido de los deberes de los Estados a investigar, juzgar, sancionar y reparar las graves violaciones de derechos humanos y los correlativos derechos de las víctimas a la verdad, la justicia y la reparación. ${ }^{114}$

La adopción de este tipo de medidas, a las que sorprendentemente se califica como "justicia" en lugar de "medidas de política pública", es justificada por sus promotores con base en la imposibilidad de satisfacer plenamente los mencionados derechos de las víctimas debido al carácter masivo de las violaciones, la necesidad de comprometer de manera notable su contenido para alcanzar acuerdos que permitan realizar procesos de transición, y las excepcionales y únicas circunstancias que rodean estos últimos. ${ }^{115}$

Sin embargo, la necesidad de una transición no es nada excepcional en los contextos en los que se producen graves violaciones de derechos humanos constitutivas de delitos internacionales. ${ }^{116}$ Cuando el desprecio por la dignidad

\footnotetext{
${ }^{111}$ Sen, Amartya, La idea de justicia, Buenos aires, Taurus, 2010, pp. 34-36.

${ }^{112}$ Para profundizar: Clamp, Kerry y Doak, Jonathan, "More than words: restorative justice concepts in transitional justice settings", International Criminal Law Review, vol. 12, núm. 3, julio de 2012, pp. 339-360.

${ }^{113}$ Cárdenas, Juan Camilo et al., "The hidden face of justice: fairness, discrimination and distribution in transitional justice processes”, Peace Economics, Peace Science, \& Public Policy, vol. 20, núm. 1, enero de 2014, p. 34.

114 Galaín, P., “A modo de conclusión”, en Galaín, P. (ed.), ¿Justicia de transición? mecanismos jurídicos y políticos para la elaboración del pasado, Valencia, Tirant lo Blanch, 2015, pp. 391 y ss.

${ }^{115}$ Uprimny Yepes, Rodrigo y otros, Justicia para la paz. Crímenes atroces, derecho a la justicia y paz negociada, Bogotá, p. 101.

${ }^{116}$ Luban, David, “A theory of crimes against humanity”, Yale International Law Journal, vol. 29, 2004, p. 90.
} 
Esta revista forma parte del acervo de la Biblioteca Jurídica Virtual del Instituto de Investigaciones Jurídicas de la UNAM

humana, ya sea por el deterioro de los sistemas políticos, la existencia de conflictos armados o ambos, alcanza los niveles de violencia propios de situaciones de genocidio, crímenes de lesa humanidad o prácticas generalizadas de crímenes de guerra, la necesidad de procesos de transición se presenta como un hecho ineludible. En consecuencia, las medidas de política pública que se engloban en el concepto de justicia de transición están dirigidas a tener un impacto directo en el tratamiento general otorgado a los crímenes internacionales, tanto desde la perspectiva de los deberes de los Estados, como de los derechos de las víctimas.

Para otros autores, el concepto de "justicia de transición" no puede limitarse a medidas relativas al esclarecimiento de la verdad, la investigación, el enjuiciamiento y la sanción de los responsables y la reparación a las víctimas, sino que ha de extenderse a la adopción de políticas públicas dirigidas a abordar las causas sociales, económicas, políticas y culturales de la violencia. Como Félix Reátegui ha subrayado,

...los retos y deberes que las sociedades que emergen del autoritarismo o de la violencia armada afrontan, no son, solamente, los relativos al logro de una transición efectiva en términos de institucionalidad política; son, también y centralmente, tareas referidas a la provisión de medidas de justicia frente a las víctimas de violaciones de derechos humanos, al esclarecimiento y el reconocimiento colectivo y crítico de los hechos del pasado, y en última instancia, a la creación de condiciones para tener una paz sostenible. ${ }^{117}$

De esta manera, el concepto de justicia de transición desborda el ámbito del derecho, y se nutre de un universo de variables políticas, sociales, económicas y culturales que conforman la situación en la que debe aplicarse.

A la división existente sobre el alcance y naturaleza de las medidas de política pública incluidas en el concepto de justicia de transición se une la pretensión de algunos de sus proponentes de aplicarlo tanto a los procesos de retorno a la democracia como a los dirigidos a la consecución de la paz en el medio del conflicto. Es por ello que autores como Farid Benavides sostienen que este concepto

...está cargado con una fuerte ambigüedad, pues se aplica por igual a situaciones de transición desde gobiernos autoritarios, formando parte de los estudios de la transición a la democracia, así como a situaciones de paso de una situación de conflicto armado,

\footnotetext{
${ }^{117}$ Reátegui, Félix, Introducción. Justicia transicional. Manual para América Latina, Nueva York-Brasilia, Centro Internacional para la Justicia Transicional-Comisión de Amnistía, 2011, p. 36.
} 
Esta revista forma parte del acervo de la Biblioteca Jurídica Virtual del Instituto de Investigaciones Jurídicas de la UNAM

internacional y no internacional, a una situación de paz, formando de ese modo parte de los estudios de paz. ${ }^{118}$

A la luz de tan notables ambigüedades que rodean al concepto de justicia de transición, no es posible afirmar que el mismo forme parte del derecho internacional consuetudinario, mucho menos del derecho imperativo, puesto que no sólo carece de la suficiente determinación y especificidad de contenido, sino que no disfruta del necesario consenso para su consolidación normativa. Es por ello que dicho concepto sólo aparece recogido normativamente en instrumentos que plantean principios de su aplicación, pero que en la realidad se encuentran lejos de constituirse como normas duras de derecho internacional. ${ }^{119}$

En consecuencia, los estándares promovidos desde la justicia de transición en materia de cumplimiento con los postulados de la lucha contra la impunidad, la reparación a las víctimas y la obtención de la verdad, deberán ser compatibles con la responsabilidad internacional penal por la comisión de delitos internacionales y los correlativos deberes de investigación, sanción y reparación de los Estados, y derechos de las víctimas a la verdad, la justicia y la reparación.

\section{CONCLUSIÓN}

La necesidad de redefinir el ámbito de actuación del concepto

de justicia de transición partiendo del paradigma "no hay

paz sin justicia"

El bien jurídico protegido por los crímenes de lesa humanidad forma parte del fundamento último sobre el que se construye el actual ordenamiento jurídico internacional. Además, en la actualidad se encuentra consolidada tanto en el derecho internacional general como en el derecho convencional, la regulación de la categoría de los crímenes de lesa humanidad y sus efectos jurídicos, entre los que cabe destacar: (i) la prohibición expresa de actos graves de violencia sistemática o generalizada contra la población civil; (ii) la atribución de responsabilidad internacional penal frente al conjunto de la sociedad internacional a los máximos

\footnotetext{
${ }^{118}$ Benavides, Farid, Justicia en épocas de transición, Bogotá, Ibáñez, 2013, p. 9.

${ }^{119}$ Véase por ejemplo, ECOSOC, Comisión de Derechos Humanos, Subcomisión de Prevención de Discriminaciones y Protección de las Minorías. La cuestión de la impunidad de los autores de violaciones de los derechos humanos (civiles y políticos). Informe final elaborado y revisado por M. Joinet en aplicación de la decisión 1996/119 de la Subcomisión, E/CN. 4/Sub. 2/1997/20/Rev.1,2 octubre de 1997, y The Belfast Guidelines on Amnesty and Accountability. 2013. En línea http://www.ulster.avs.uk/_data/assets/pdf_file/0005/57839/TheBelfastGuidelinesFINAL_000.pdf.
} 
Esta revista forma parte del acervo de la Biblioteca Jurídica Virtual del Instituto de Investigaciones Jurídicas de la UNAM

responsables de tales conductas, y (iii) la imprescriptibilidad y prohibición de leyes de amnistía frente a dicha responsabilidad internacional penal.

En cuanto al carácter imperativo o de ius cogens de esta regulación, la jurisprudencia consolidada de la Corte IDH afirma la naturaleza de derecho imperativo de la prohibición expresa dirigida a los Estados, de incurrir en actos graves de violencia sistemática o generalizada contra la población civil. Además, en los casos Almonacid Arellano y otros vs. Chile, Penal Miguel Castro Castro y La Cantuta, la Corte IDH ha afirmado también el carácter de ius cogens de la normativa que atribuye responsabilidad internacional penal a quienes incurren en crímenes de lesa humanidad, así como de la que afirma la imprescriptibilidad de tal responsabilidad y prohíbe las leyes de amnistía. Por su parte, la jurisprudencia de los tribunales internacionales penales, particularmente la del TPIY, ha subrayado el carácter imperativo de las normas que atribuyen responsabilidad internacional penal a quienes incurren en genocidio, crímenes de lesa humanidad y crímenes de guerra.

No ha sido, sin embargo, tan vocal en este sentido la jurisprudencia de la CIJ y la CEDH, al analizar la posible colisión entre la categoría de los crímenes de lesa humanidad y sus efectos jurídicos, y las normas consuetudinarias que establecen el principio de inmunidad de jurisdicción de los Estados. Ambas cortes han aceptado la existencia de crímenes internacionales de ius cogens, si bien en el caso de la CEDH sus pronunciamientos se han limitado al delito de tortura. Sin embargo, han guardado silencio a la hora de extender dicho carácter imperativo a sus efectos, al centrar sus conclusiones en que la naturaleza procesal del principio de inmunidad de jurisdicción del Estado no puede entrar nunca en conflicto con la naturaleza sustantiva de la regulación que proscribe los delitos internacionales de ius cogens.

Por último, es necesario subrayar que frente a la regulación internacional del fenómeno de la lesa humanidad, no es posible afirmar que la aplicación del concepto de justicia de transición haga parte del derecho internacional general o convencional, y mucho menos del derecho imperativo, puesto que carece de la suficiente determinación y especificidad de contenido, y no disfruta del necesario consenso para su consolidación normativa. En consecuencia, al no contar la justicia de transición con un apoyo normativo de la misma naturaleza del que es propio de los crímenes de lesa humanidad y sus efectos, se plantea la necesidad de que aquélla redireccione su actuación hacia la búsqueda de fórmulas, que partiendo epistemológicamente del respeto al paradigma "no hay paz sin justicia" como 
Esta revista forma parte del acervo de la Biblioteca Jurídica Virtual del Instituto de Investigaciones Jurídicas de la UNAM

condición de validez, permitan aligerar algunas de las tensiones observadas en los actuales procesos de transición.

\section{BIBLIOGRAFÍA}

\section{Libros}

AmBos, Kai (coord.), La nueva justicia penal supranacional, Valencia, Tirant lo Blanch, 2002.

\section{___, La Corte Penal Internacional, Buenos Aires, Rubinzal-Culzoni, 2007.}

Aust, Anthony, Handbook of International Law, 2a. ed., Oxford, Oxford University Press, Kindle Edition, 2007.

ARENDT, Hanna, Eichmann in Jerusalem: a Report on the Banality of Evil, Penguin Group, 1963.

Bassiouni, Cherif, Crimes Against Humanity-Historical Evolution and Contemporary Application, Cambridge, Cambridge University Press, 2011.

_-_, Post-Conflict Justice, Transnational Publishers, Nueva York, Ardsley, 2002.

BenAVIDES VAnegas, Farid, Justicia en épocas de transición, conceptos, modelos, debates, experiencias, Barcelona, Institut Catalá International per la Pau, 2011.

BENAVIDES, FARID, Justicia en épocas de transición, Bogotá, Ibáñez, 2013.

BRotons, Remiro y otros, Derecho internacional, 2a. ed., Valencia, Tirant lo Blanch, 2007.

CASAdo RAIGón, Rafael, Notas sobre el ius cogens internacional, Córdoba, 1991.

CASTRO, Carlos (coord.), Manual de derecho penal, parte especial, Bogotá, Editorial Universidad del Rosario y Temis, 2011, t. I.

CORTÉs BeCHIARELLI, E. et al. (coords.), Estudios penales en recuerdo del profesor Ruiz Antón, Valencia, Tirant lo Blanch, 2003.

Chevallier, Jean-Jaques, Los grandes textos políticos, Madrid, Aguilar Editores, 1980.

EL ZEIDY, Mohamed, The Principle of Complementarity in International Criminal Law. Origin, Development and Practice, Martinus Nijhoff Publishers, 2008.

GalAín, P. (ed.), ¿justicia de transición? Mecanismos jurídicos y políticos para la elaboración del pasado, Tirant lo Blanch, 2015.

Gómez Robledo, A., El ius cogens internacional, México, UNAM, 1982. 
Esta revista forma parte del acervo de la Biblioteca Jurídica Virtual del Instituto de Investigaciones Jurídicas de la UNAM

González Morales, Felipe, Sistema inter-americano de derechos humanos: transformaciones y desafíos, Valencia, Tirant lo Blanch, 2013.

JAKOBS, Gunther y CANCIO Melí, Manuel, Derecho penal del enemigo, Madrid, Editorial Civitas, 2006.

LOSANO y MUÑOz, Conde (coords.), El derecho ante la globalización y el terrorismo, "cedant arma togae", Valencia, Tirant lo Blanc, 2004.

Nimmo, John, The Works of the Right Honourable Edmund Burk, Londres, 1899.

OLASOLO, Héctor, Introducción al derecho internacional penal, México, Tirant lo Blanch-Universidad del Rosario-Instituto Ibero-Americano de la Haya (IIH), 2014.

_-_, Corte Penal Internacional: ¿Dónde investigar?, Valencia, Tirant lo Blanch, 2003.

- - y PÉREz CePedA, Ana, Terrorismo y conflicto armado, Valencia, Tirant lo Blanch, 2008.

ReÁTEGUI, Félix, Introducción. Justicia transicional. Manual para América Latina, Nueva York-Brasilia, Centro Internacional para la Justicia Transicional-Comisión de Amnistía, 2011.

Sen, Amartya, La idea de justicia, Buenos aires, Taurus, 2010.

WERLE, Gerad, Tratado de derecho penal internacional, 2a. ed., Valencia, Tirant lo Blanch, 2010.

UPRIMNY YePES, Rodrigo y otros, Justicia para la paz. Crímenes atroces, derecho a la justicia y paz negociada, Bogotá, 2014.

Zaffaroni, E. R. et al., Derecho penal. Parte general, Buenos Aires, Ediar, 2000.

\section{Artículos académicos}

Ambos, Kai, “Crímenes de lesa humanidad y la Corte Penal Internacional”, Cuadernos de Derecho Penal, Bogotá, 2013.

ABASS, Ademola, "The Competence of the Security Council to Terminate the Jurisdiction of the International Criminal Court", Texas International Law Journal, vol. 40, 2005.

ABello, Ricardo, “Introducción al estudio de las normas de ius cogens en la Comisión de Derecho Internacional", Revista Universitas, Bogotá, 2011.

BASSIONI, Cheriff, "International Crimes: ius cogens and Obligatio erga omnes", Law and Contemporany Problems, vol. 59, núm.4, 1996. 
Esta revista forma parte del acervo de la Biblioteca Jurídica Virtual del Instituto de Investigaciones Jurídicas de la UNAM

CÁRDENAS, Juan Camilo et al., "The Hidden Face of Justice: Fairness, Discrimination and Distribution in Transitional Justice Processes", Peace Economics, Peace Science, \& Public Policy, vol. 20, núm. 10. de enero de 2014.

CASTRo CuenCA, Carlos Guillermo, "Algunos lineamientos sobre la legitimidad del injusto en los bienes jurídicos supraindividuales", Problemas actuales de derecho penal, Santiago, 2006.

CHETAIL, Vincent, "The Contribution of the International Court of Justice to the International Humanitarian law", International Review of the Red Cross, vol. 85, núm. 850, 2003.

CLAMP, Kerry y DOAK, Jonathan, "More than Words: Restorative Justice Concepts in Transitional Justice Settings", International Criminal Law Review, vol. 12, núm. 3, julio de 2012.

DAdRIAN, Vahakan, "D'amatoLaw: the World War I Armenian Case and its Contemporary Legal Ramifications", Yale Journal of International Law, núm. 14, 221, 1989.

D'Amato, Anthony, "Is a Bird, is a Plane, no is ius cogens", Connecticut Journal of International Law, vol. 6, núm. 1, otoño de 1990.

GHeAuS, Anca, "The Feasibility Constraint on the Concept of Justice", Philosophical Quarterly, vol. 63, núm. 252, julio de 2013.

LUBAN, David, "A theory of crimes against humanity", Yale International Law Journal, vol. 29, 2004

___, Una teoría de los crímenes contra la humanidad, Bogotá, Temis, 2011.

MATAS, David, "Prosecuting crimes against humanity: the lessons of World War I", Fordham International Law Journal, núm. 13, 86, 1990

OlASOLO, Héctor, “Dignidad humana, derecho internacional penal y justicia transicional", Revista Estudios Socio-Jurídicos, Bogotá, vol. 16, 2014.

_-_, “Los exámenes preliminares de la Corte Penal Internacional en América Latina: el caso colombiano y su impacto sobre futuras negociaciones de paz en la región", Anuario de Derechos Humanos, Santiago, núm. 14, 2014.

OOSTHIIZEN, Gabriel, "Some preliminary remarks on the relationship between the envisaged International Criminal Court and the UN Security Council", Netherlands International Law Review, vol. 46, 1999. 
Esta revista forma parte del acervo de la Biblioteca Jurídica Virtual del Instituto de Investigaciones Jurídicas de la UNAM

PetsChe, Markus, "Jus cogens as a vision of international legal order?", Pennsilvania State International Law Review, núm. 20, 258, 2011.

SCHWELB, Egon, "Crimes against humanity", British Yearbook of International Law, Londres, núm. 23, 178, 1946.

VARÓN, Antonio, “Orden público internacional y normas ius cogens: una perspectiva desde la Comisión de Derecho Internacional y la Convención de Viena de 1969", Diálogo de Saberes, vol. 32, fasc. 32, 2010.

VERDROSS, Alfred, "Forbidden treaties in international law", American Journal of International Law, núm. 31, 1937.

Vervaele, John, "La legislación antiterrorista en Estados Unidos: inter arma silent leges", Revista de Derecho y Proceso Penal, Madrid, núm. 14, 2005. 